Nikki M. Lowrey ${ }^{1}$

\title{
Analysis of Risks to Oxygen Systems from Particulate and Fiber Contaminants and Derivation of Cleanliness Requirements
}

\begin{abstract}
It has been well documented in the literature that contamination within oxygen systems can create significant fire hazards. Cleanliness limits for nonvolatile residues, ranging from 10 to $500 \mathrm{mg} / \mathrm{m}^{2}$, have been established for various industries and types of oxygen systems to reduce the risk of ignition of flammable organic films. Particulate cleanliness limits used for oxygen systems vary considerably. Maximum allowed particle size, quantity limits, and allocations for fibers or metallic particles are all variables seen in aerospace cleanliness limits. Particles are known to have the potential to ignite within oxygen systems and must be limited to prevent fires. Particulate contamination may also pose risks to the performance of oxygen systems that are unrelated to ignition hazards. An extensive literature search was performed to better understand the relative importance of particle ignition mechanisms versus other deleterious effects of particles on oxygen systems and to identify rationale for derivation of particulate cleanliness limits for specific systems. The identified risks of different types and sizes of particles and fibers were analyzed. This paper summarizes the risks identified and rationale that may be used to derive particulate cleanliness limits for specific oxygen systems.
\end{abstract}

KEYWORDS: contamination, fiber, particulate, oxygen service, liquid oxygen

\footnotetext{
Notice for Copyrighted Information

This manuscript has been authored by employees of Jacobs Technology, Inc., under Contract NNM12AA41C with the National Aeronautics and Space Administration. The United States Government has a nonexclusive, irrevocable, worldwide license to prepare derivative works, publish or reproduce this manuscript, and allow others to do so, for United States Government purposes. Any publisher accepting this manuscript for publication acknowledges that the United States Government retains such a license in any published form of this manuscript. All other rights are retained by the copyright owner.
}

\footnotetext{
${ }^{1}$ Senior Contamination Control Engineer, Jacobs Technology, Inc. / Jacobs ESSSA Group, 1500 Perimeter Parkway, Suite 400, Huntsville, AL 35806. This work performed under NASA contract NNM12AA41C.
} 
Particulate and Fiber Contaminants in Oxygen Systems 


\section{Introduction}

It has been well documented in the literature that contamination within oxygen systems can create significant fire hazards. [1] Cleanliness limits for nonvolatile residues (NVR), ranging from 10 to $500 \mathrm{mg} / \mathrm{m}^{2}$, have been established for various industries and types of oxygen systems to reduce the risk of ignition of flammable organic films. [2] Particulate cleanliness limits used for oxygen systems vary considerably. For some low pressure oxygen system applications, qualitative inspection methods such as visual inspection or a "wipe test" are considered adequate to verify particulate cleanliness. Other applications require verification to specified particulate size and quantity limits. Even within specific applications such as aerospace propulsion, specifications for maximum allowed particle size, quantity limits, and allocations for specific types of particles such as fibers or metallic particles vary considerably.

Little has been published regarding how particulate cleanliness requirements should be established for specific oxygen systems or what design factors may drive these requirements. Particles are known to have the potential to ignite within oxygen systems and must be limited to prevent fires. Particulate contamination may also pose risks to the performance of oxygen systems that are unrelated to ignition hazards. Particles and fibers may, for example, restrict filter flow, plug critical orifices, or interfere with the performance of valves and seals. A system performance requirement may drive the need for a more stringent particulate cleanliness limit than required to minimize the risk of a fire.

In 2012, the author was tasked to perform an analysis to determine whether the internal contamination limits for a liquid propulsion test system could be revised to provide an allocation for fibers beyond the established particulate limits. An extensive literature search was performed to better understand the relative importance of particle ignition mechanisms versus other deleterious effects of particles on oxygen systems and to identify rationale for derivation of particulate and fiber cleanliness limits for specific systems. This paper summarizes the risks identified and approach used to assess whether an allocation could be safely accommodated for fibers larger than the established limits for particles for a liquid oxygen (LOX) /liquid hydrogen (LH2) propulsion system. This is one example of an approach that may be used to derive particulate cleanliness limits for specific oxygen systems. The particulate contamination risks identified in this paper should be considered only a starting point for analysis of a specific oxygen system and may not be complete for systems significantly different from the one analyzed. For example, specific types of particulate may present an unacceptable health hazard when present in breathing oxygen systems.

\section{Background and Analytical Approach}

A particle is any minute quantity of matter, metallic or non-metallic, with observable length, width, and thickness. [3] Particulate contaminants within liquid bipropellant systems can have a number of detrimental effects on system performance and safety. They can plug or restrict flow through filters and orifices and can create leak paths or mechanical interference in pumps, valves, and regulators. In gaseous or liquid oxygen systems (GOX/LOX), particles can, under 
certain conditions, cause impact ignition. [1] Both particulate and film residue contaminants can be ignited in GOX/LOX systems by other mechanisms.

A fiber is defined as a particle having a length-to-width ratio (aspect ratio) of 10 to 1 or greater. [2] [3] Most fiber contaminants, such as cotton clothing fibers, have a length-to-width ratio many times greater than this. Some cleaning specifications used within the aerospace industry have also stated that a fiber must have a length of 100 micrometers $(\mu \mathrm{m})$ or greater [2, $4,5,6]$, must have a diameter of less than $25 \mu$ m [7], must be nonmetallic [6, 8, 9] and/or must be flexible. [9]

MSFC-SPEC-164, Cleanliness of Components for Use in Oxygen, Fuel, and Pneumatic Systems [3], has established quantitative limits for particulate and NVR contamination in liquid bipropellant systems manufactured or refurbished at or for NASA's George C. Marshall Space Flight Center (MSFC). The particulate levels in MSFC-SPEC-164C are shown in Table 1. The baseline version of MSFC-SPEC-164, released in 1962, specified one quantified limit for particulate contamination that was applied to all components. Three additional classes of particulate cleanliness were added in 1994 (Revision B) [10] with the original particulate cleanliness requirement retained as Class I. Class I, which permits one particle up to $2500 \mu \mathrm{m}$ but severely restricts the presence of particles down to $175 \mu \mathrm{m}$, was discontinued in revision D. The "no silting" restriction was added in revision B. Silting is defined as an accumulation of minute particles in the size range not normally counted but of sufficient quantity to interfere with sample analysis. [3] The limits for NVR were established in the baseline release and have never been modified.

MSFC-SPEC-164 has never included allocations or size limits for fiber contaminants as a distinct particle type. Fibers, however, are often more difficult to control than other types of particles during precision cleaning and assembly. Fibers are readily transported in air currents and deposited on hardware. Fibers also can slip through screens in cleaning equipment, defeating the filtration systems intended to keep the cleaning agent free of particulate. The presence of a fiber in a component cleanliness verification sample may result in a rejection, requiring the shop to re-clean the part and driving up processing costs.

The steps used to analyze the system tolerance for fibers were as follows:

1) Determine the technical rationale for the current particulate limits via a search for published historical rationale and by deriving them from historical system design and performance criteria.

2) Based on this rationale, identify and analyze the potential consequences of allowing fibers larger than the current particulate limits.

3) Identify other potential risks, apart from those directly related to the derived technical rationale, that must be considered and determine whether those risks are of significance.

4) Compare the fiber size and quantity limits identified for each risk scenario to determine the risk drivers and associated maximum fiber size and quantity to establish allocations. 
Table 1- Classification of Particulate Cleanliness in MSFC-SPEC-164C

\begin{tabular}{|c|c|c|}
\hline CLASS & $\begin{array}{l}\text { PARTICLE SIZE IN } \\
\text { MICRONS }\end{array}$ & MAX. NUMBER PER $0.1 \mathrm{~m}^{2}$ \\
\hline I & $\begin{array}{c}>2500 \\
700<x \leq 2500 \\
175<x \leq 700 \\
\text { NO SILTING }\end{array}$ & $\begin{array}{l}0 \\
1 \\
5\end{array}$ \\
\hline II & $\begin{array}{c}>1000 \\
700<x \leq 1000 \\
175<x \leq 700 \\
\text { NO SILTING } \\
\end{array}$ & $\begin{array}{c}0 \\
40 \\
150\end{array}$ \\
\hline III & $\begin{array}{c}>800 \\
\text { NO SILTING }\end{array}$ & 0 \\
\hline III $X$ & $\begin{array}{c}>800 \\
175<\mathrm{X} \leq 800 \\
\text { NO SILTING }\end{array}$ & $\begin{array}{l}0 \\
5\end{array}$ \\
\hline IV & $\begin{array}{c}>400 \\
\text { NO SILTING } \\
\end{array}$ & 0 \\
\hline IV X & $\begin{array}{c}>400 \\
175<\mathrm{x} \leq 400 \\
\text { NO SILTING }\end{array}$ & $\begin{array}{l}0 \\
5\end{array}$ \\
\hline $\mathrm{V}$ & VISUALLY CLEAN/NO S & ING \\
\hline
\end{tabular}

\section{Precedent for Fiber Allocations}

A literature search was performed to determine whether there is current or historical precedent for fiber allocations in LOX/LH2 systems. Several significant sources were identified where fiber limits were established that exceeded the particle size limits for LOX/LH2 propulsion systems as well as high pressure gaseous oxygen systems.

The Compressed Gas Association standard for cleaning equipment for oxygen service clearly allows for the presence of lint fibers as long as there are no accumulations. [11] The section on visual ultraviolet inspection states that "some materials such as cotton lint that fluoresce are acceptable unless present in excessive amounts". This document further states that when quantified limits for particulate are specified, typical specifications limit particles to no more than $1000 \mu \mathrm{m}$, with no more than 20 particles/ $/ \mathrm{ft}^{2}\left(0.1 \mathrm{~m}^{2}\right)$ between $500 \mu \mathrm{m}$ and $1000 \mu \mathrm{m}$, and isolated fibers of lint no longer than $2000 \mu \mathrm{m}$ with no accumulation. The repeated use of the 
Particulate and Fiber Contaminants in Oxygen Systems

terms "cotton lint" and "lint fibers" implies that these fibers are assumed to be nonmetallic, as opposed to metal "filings" which are noted elsewhere in the document as another form of contamination.

The NASA Glenn Research Center (GRC) Safety Manual specifies contamination limits for gaseous/liquid oxygen service in GRC test facility systems. [7] The cleanliness limits include allocations for particles and fibers in defined size ranges, with allowed particles no larger than $300 \mu \mathrm{m}$ (500 $\mu \mathrm{m}$ for pressure gauges and transducers) and fibers no larger than $1875 \mu \mathrm{m}$ in length and $25 \mu \mathrm{m}$ in diameter.

A detailed survey was performed in 1972 by the Aerospace Safety Research and Data Institute (ASRDI), NASA - Lewis Research Center, to document current practice in the aerospace industry for cleaning of oxygen systems. [8] Twenty oxygen system cleanliness specifications were referenced in the survey report, including specifications for spacecraft and aircraft breathing oxygen systems, manned launch vehicle and missile propulsion systems, and commercial systems. Fourteen of these specifications contained allocations for fiber contaminants that exceeded the maximum dimension of the corresponding particle limit by a factor of two to a factor of ten. The maximum allowed fiber length was $6000 \mu \mathrm{m}$; fiber length limits around $2000 \mu \mathrm{m}$ were more common.

In addition to the above sources documenting common use of fiber allocations in the aerospace industry since the 1960's, SD 70-557-5, a sustaining engineering report from the Saturn launch vehicle S-II program, recommended specific fiber allocations for future S-II production. [12] This document, starting from MSFC-SPEC-164A as the basis, recommended that the allocation for one particle 700 to $2500 \mu \mathrm{m}$ per square foot be restricted to nonmetallic fibers only. The recommendations from this report were not captured in subsequent revisions of MSFC-SPEC-164. No more S-II stages were built.

\section{Derivation of Fluid System Particulate Limits}

The Space Shuttle fluid specification imposed size limits of $400 \mu \mathrm{m}$ and $800 \mu \mathrm{m}$, respectively, for allowable particulate in LH2 and LOX for the main propulsion systems. [6] These are reported to have been derived from the smallest system orifice diameters using the conservative three ball approach as a goal. This approach uses the three ball equation to establish the maximum particle diameter that will permit three balls (contaminant particles) to pass through the smallest system orifice simultaneously. Limiting all particulate contamination to below this size will minimize the risk that particulate will lodge in a critical orifice, blocking or restricting propellant flow. Such blockage or restriction could inhibit engine performance during launch and result in a loss of mission.

The formula for calculating the diameters of a specified number of circles of equal size that will fit side by side within a larger circle is:

$$
\mathrm{d}=\mathrm{D} \times \sin (\pi / \mathrm{x}) /(1+\sin (\pi / \mathrm{x}))
$$


where $\mathrm{d}=$ the smaller circle diameter, $\mathrm{D}=$ the larger circle diameter, $\mathrm{x}=$ the number of circles to fit ring-like $(x=2,3, \ldots)$.

For the three ball calculation, the smaller circle diameter (d) corresponds to the diameter of the maximum allowable particle size, the larger circle diameter (D) is the orifice size, and the number of circles to fit $(\mathrm{x})$ is three. Therefore:

$$
\mathrm{d}=\mathrm{D} \times \sin (\pi / 3) /(1+\sin (\pi / 3))=\mathrm{D} \times(0.4641)
$$

7/16 of the orifice diameter ( $\mathrm{D} \times(.4375)$ ) may be used as a simple, conservative approximation.

Calculating with the three ball equation, particle size limits of $400 \mu \mathrm{m}$ for the LH2 system and $800 \mu \mathrm{m}$ for the LOX system indicate that the smallest downstream orifices to be protected (ideally) are equal to or larger than $862 \mu \mathrm{m}$ (0.034 inch) and $1724 \mu \mathrm{m}$ (0.068 inch) respectively.

MSFC-SPEC-164 Revision B established Class III and Class IV for oxygen system components and hydrogen system components, respectively, that feed the engine downstream of the propellant tank filter screens. A less stringent limit, Class II, was established for the tanks. The orifice sizes for the tank feed filters are the same as the maximum allowed particle size for the propellants; i.e. $400 \mu \mathrm{m}$ and $800 \mu \mathrm{m}$.

The smallest particle size with limits in MSFC-SPEC-164, $175 \mu \mathrm{m}$, corresponds to the maximum allowable particle size for a $400 \mu \mathrm{m}$ orifice using the simple approximation (7/16) of the three ball equation. The no-silting limit, added in revision $\mathrm{B}$, was likely established to assure accurate particle counts and to avoid the presence of excessive quantities of finer contaminants that could agglomerate and act as larger particles or as combustible matter. At least one industry study indicated that, under some circumstances, an excessive quantity of particles smaller than $40 \mu \mathrm{m}$ could cause an ignition due to particle impact. [13] Silting may also be a warning sign that hardware has corroded or the cleaning system has become contaminated.

The original particle limits, now Class I, permitted five particles $175 \mu \mathrm{m}$ to $700 \mu \mathrm{m}$ per square foot and 1 particle per square foot up to $2500 \mu \mathrm{m}$. It has been reported that these larger particle allocations were derived from actual "field tests" at the Kennedy Space Center complexes and represent the maximum cleanliness results obtainable in the field during the 1960 to 1964 time period. [8]

It should be noted that components for NASA breathing oxygen systems, and for ambient and cryogenic helium regulator sets and other pneumatic system components integral to bipropellant propulsion systems, require protection from particulate smaller than $175 \mu \mathrm{m}$. Cleaning of these components is specified to meet a more stringent cleanliness level than specified in MSFC-SPEC-164, usually per IEST-STD-CC1246, Product Cleanliness Levels and Contamination Control Program, [14] or a modification thereof. [6] 


\section{Fiber Limits Based on Critical Orifice and Filter Plugging}

Analysis of the tolerance of a system to fiber contamination based on orifice plugging must consider contaminant locations upstream and downstream of filters. Fiber contaminants downstream of the propellant tank feed filters must not present a greater risk of plugging the critical engine orifices than the baseline $400 \mu \mathrm{m}$ or $800 \mu \mathrm{m}$ particle size limits. Fiber contaminants upstream of the tank filters must not present a greater risk of restricting flow through these screens. Fibers from the tanks that pass through the tank filter screens lengthwise during operation also must not present an increased risk to downstream components.

Using the 10 to 1 aspect ratio for fiber width to length as worst case, several scenarios are considered for the potential to plug or restrict $400 \mu \mathrm{m}$ or $800 \mu \mathrm{m}$ orifices. The critical orifices downstream are assumed to be significantly larger, further reducing the probability that fibers permitted based on the tank filter pore size will restrict flow.

Scenario 1: Fibers pass through the orifice lengthwise

Assuming that all fibers entrained in flowing fluid are straight fibers that will orient lengthwise, passing any orifice larger than the width of the fiber, the maximum allowable particle length is theoretically unlimited. The allowable particle width would be the same as the allowed particle diameter. However, fibers pose additional risks for orifice plugging beyond particulate. The increased length of a fiber increases the time required for that fiber to pass through an orifice. This greatly increases the probability of orifice plugging due to multiple fibers or particles encountering an orifice simultaneously. Assuming that the ratio of the downstream critical orifice to the upstream filter screen adheres to the three ball calculation, limiting the width of all fibers in the system, downstream or upstream of the tank filter screens, to that based on the three ball calculation for the screen pore size rather than the downstream orifice size will yield an allowed fiber width of $(0.4641$ x 0.4641$)$ or $21.5 \%$ of the downstream orifice size. At maximum packing density, the downstream orifice will pass as many as 16 fibers of this width without plugging. ${ }^{2}$

Allowing fibers in each system with a maximum length of 10 times the approximated (7/16) three ball calculation for the tank filter screen pore size, $1750 \mu \mathrm{m}$ (for LH2) and $3500 \mu \mathrm{m}$ (for LOX), and quantities limited by the "no silting" requirement, would appear to be conservative. Such fibers at the maximum aspect ratio of 10 to 1 would be clearly visible to the unaided eye and would not pass visual inspection. Fibers of these lengths with widths less than $50 \mu \mathrm{m}$ are more typical of environmental fibers such as clothing fibers. These would pose an insignificant risk of critical orifice plugging. Table 2 shows the number of fibers of different diameters that could theoretically pass through an orifice simultaneously, based on best known packing calculations of equal circles within a larger circle. [15]

\footnotetext{
${ }^{2}$ Calculation of the packing of equal circles beyond seven within a larger circle becomes complicated as there is extra space. Several internet sources on circle packing point to this article for packing of 16 equal circles into a larger circle: Goldberg, M., Packing of 14, 16, 17, and 20 Circles in a Circle, Math. Mag. 44, 134-139, 1971. [15]
} 
Table 2 - Number of fibers that can pass lengthwise through an orifice simultaneously

\begin{tabular}{|c|c|c|c|c|}
\hline & \multicolumn{4}{|c|}{ ORIFICE SIZE } \\
\hline $\begin{array}{c}\text { FIBER } \\
\text { DIAMETER }\end{array}$ & $400 \mu \mathrm{m}$ & $862 \mu \mathrm{m}^{\mathrm{a}}$ & $800 \mu \mathrm{m}$ & $1724 \mathrm{~m}^{\mathrm{a}}$ \\
\hline $100 \mu \mathrm{m}$ & 11 & 59 & 50 & 249 \\
\hline $70 \mu \mathrm{m}$ & 24 & 124 & 106 & 519 \\
\hline $50 \mu \mathrm{m}$ & 50 & 249 & 213 & 1032 \\
\hline
\end{tabular}

a. Calculated downstream critical orifice sizes assuming that the filter screen pore size was selected based on the three ball calculation.

Scenario 2: Fibers passing through the orifice are bent double or broken in half

Scenario 1 assumes that each fiber will align with the fluid flow and pass through the orifice end-on. If an accumulation of fibers are deposited on a filter screen prior to initiation of critical flow, they may either remain in place, be swept through lengthwise, or pass through the orifice doubled should they either fold in two or break under the force of the flow thus acting as two fibers. Assuming that these fibers pass through doubled; the number of fibers that could theoretically pass the orifice is one half the numbers shown in Table 2, to the next lower even number of fibers.

Given that fibers are much longer than particles and therefore take longer to pass through an orifice, the opportunity for fibers to pass through an orifice simultaneously is much greater than particles. There is, therefore, some question whether $100 \mu \mathrm{m}$ diameter fibers should be permitted in a system with a $400 \mu \mathrm{m}$ critical orifice, where six folded or broken fibers could block an orifice. Narrowing the allowable fiber diameter to $70 \mu \mathrm{m}$ would add conservatism and still accommodate the most common and troublesome environmental fibers. Even if the critical orifice is only slightly larger than the filter pore size, the number of fibers that may pass lengthwise, even doubled over, increases substantially. For example, a $450 \mu \mathrm{m}$ diameter critical orifice will simultaneously pass up to seven doubled $100 \mu \mathrm{m}$ wide fibers and up to 32 doubled 50 $\mu \mathrm{m}$ wide fibers. See Table 3.

The idealized case of fibers folded with a zero bend radius is unlikely. Restricting the fibers to less than $50 \mu \mathrm{m}$ diameter yields a generous margin for imperfectly folded fibers.

Filter screens used in LOX systems may be constructed of woven wire mesh, with pore size defined by an absolute glass bead rating. A square mesh orifice yields approximately $22 \%$ more flow area than a round orifice of the same width. Whereas a circular orifice will pass three particles less than 0.4641 times its diameter, a square of the same width will pass three particles less than 0.5087 times its width and the number of fibers of smaller diameter that can pass simultaneously also rises significantly. The worst case scenario shown in Table 3, where up to 
five doubled $100 \mu \mathrm{m}$ fibers will pass through a $400 \mu \mathrm{m}$ round orifice, compares to eight doubled $100 \mu \mathrm{m}$ fibers that may pass through a $400 \mu \mathrm{m}$ square orifice. This is illustrated in figure 1.

Table 3: Number of doubled fibers that can pass lengthwise through an orifice simultaneously

\begin{tabular}{|c|c|c|c|c|c|c|}
\hline & \multicolumn{5}{|c|}{ ORIFICE SIZE } \\
\hline $\begin{array}{c}\text { FIBER } \\
\text { DIAMETER }\end{array}$ & $400 \mu \mathrm{m}$ & $450 \mu \mathrm{m}$ & $862 \mu \mathrm{m}$ & $800 \mu \mathrm{m}$ & $900 \mu \mathrm{m}$ & $1724 \mu \mathrm{m}$ \\
\hline $100 \mu \mathrm{m}$ & 5 & 7 & 29 & 25 & 32 & 124 \\
\hline $70 \mu \mathrm{m}$ & 12 & 15 & 62 & 53 & 67 & 259 \\
\hline $50 \mu \mathrm{m}$ & 25 & 32 & 124 & 106 & 136 & 516 \\
\hline
\end{tabular}

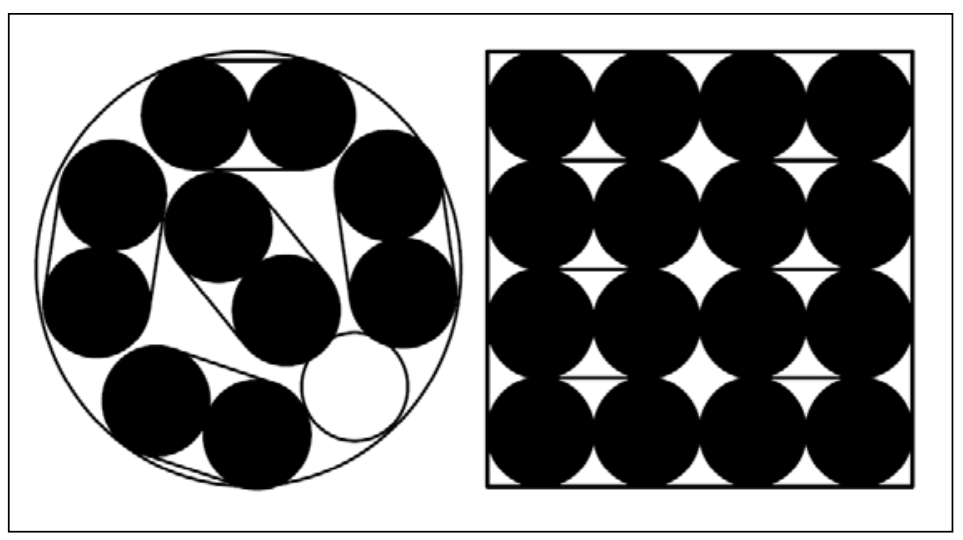

Figure 1 - Packing of doubled fibers in a square versus a circle of the same width
Scenario 3: Fibers passing through the orifice are rigid and bent or twisted

It is assumed in scenarios 1 and 2 that all of the fibers are either straight or are sufficiently flexible to pass the orifice lengthwise without interference. Natural clothing fibers including cotton, linen, and wool are twisted when observed under magnification. If these fibers are inflexible at cryogenic temperatures, they will not pass an orifice in a parallel orientation.

Fibers shorter than the width of the downstream critical orifice will pass unhindered regardless of their shape. Long, twisted, rigid fibers will most likely be captured by filters as the probability of the fibers lining up in an orderly fashion with the flow is significantly reduced. Should these rigid, twisted fibers be present downstream of the filter, where they could lodge at the entrance to a critical orifice, they will still present a significantly lower risk of restricting 
flow than spherical particles of the maximum allowed size. When the width of fibers is restricted to less than $50 \mu \mathrm{m}$, even very long fibers pose little obstacle to fluid flow or to the passage of particles restricted to 7/16 of the orifice size. This is illustrated in figure 2. Fibers would need to be tightly bent and 2.5 or more times the diameter of the orifice in length to begin to create an obstruction sufficient to collect particles within the orifice.

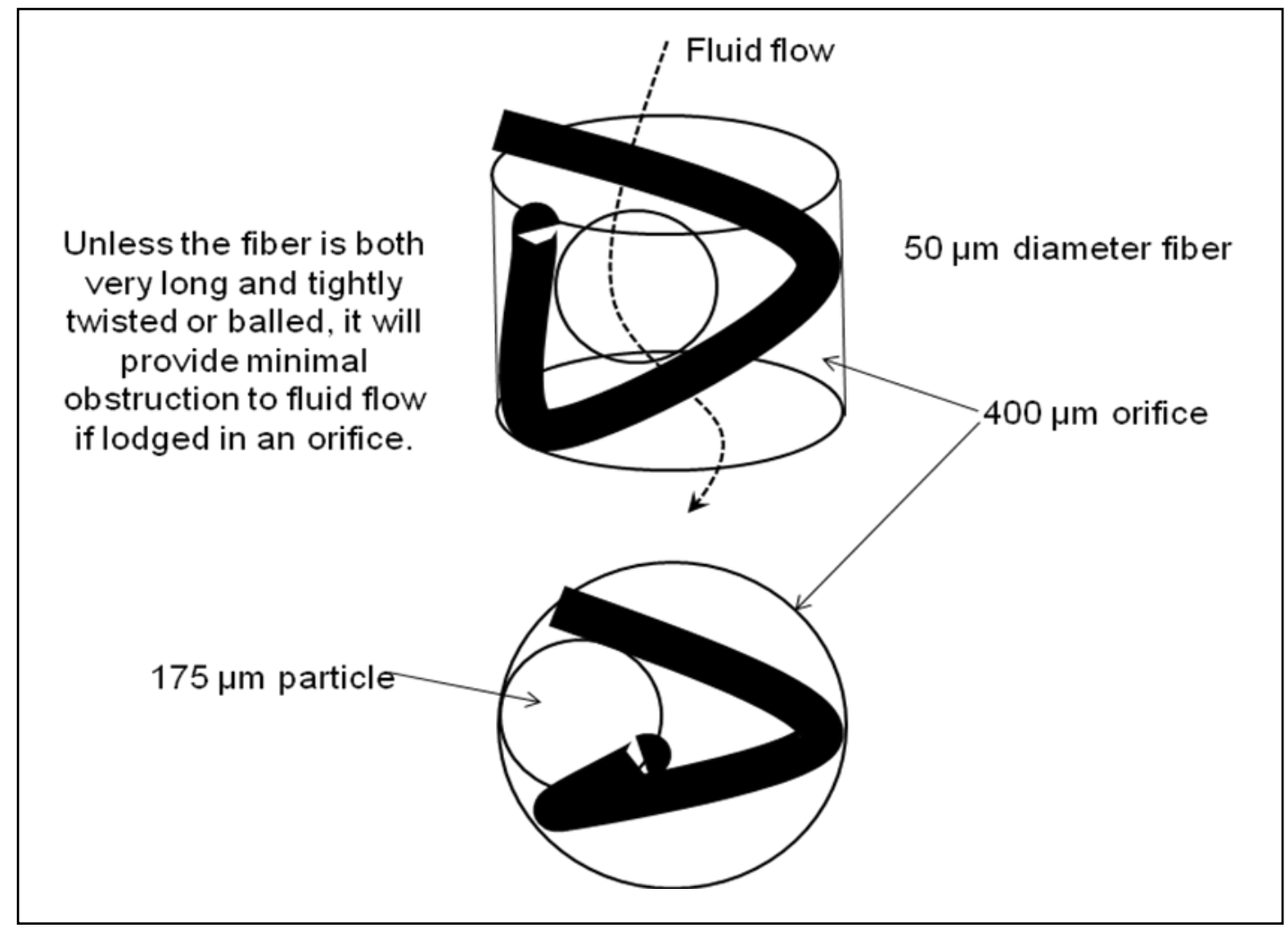

Figure 2 - Illustration of a twisted fiber lodged in an orifice

Scenario 4: Fibers and particles combine to restrict the orifice

If rigid fibers, whether straight or twisted, land across the critical orifice rather than passing through and are not simply swept aside by the fluid flow, then the flow restriction caused by either multiple fibers or combinations of fibers and particles must be considered. Assuming that not more than three particles of any type will encounter an orifice simultaneously, the worst case scenario involving a fiber is for two particles and one fiber to encounter the orifice simultaneously, with the orifice fiber landing crosswise. Using the three ball calculation to establish the particle size limit, fiber widths of up to 0.0718 times the diameter of the circular orifice will not cause an obstruction and can be permitted without limit.

$$
\mathrm{D}=[\mathrm{D} \times(0.4641)+\mathrm{D} \times(0.4641)]+\mathrm{D} \times(\mathrm{X})=>\mathrm{X}=0.0718
$$

Using the approximation of 7/16 times the orifice diameter to set the maximum particle size, the maximum fiber width becomes 1/8 times the orifice diameter. Thus, for a $400 \mu \mathrm{m}$ orifice and a maximum particle size of $175 \mu \mathrm{m}$, fibers up to $50 \mu \mathrm{m}$ in diameter can be allowed without limit. This is illustrated in figure 3. 


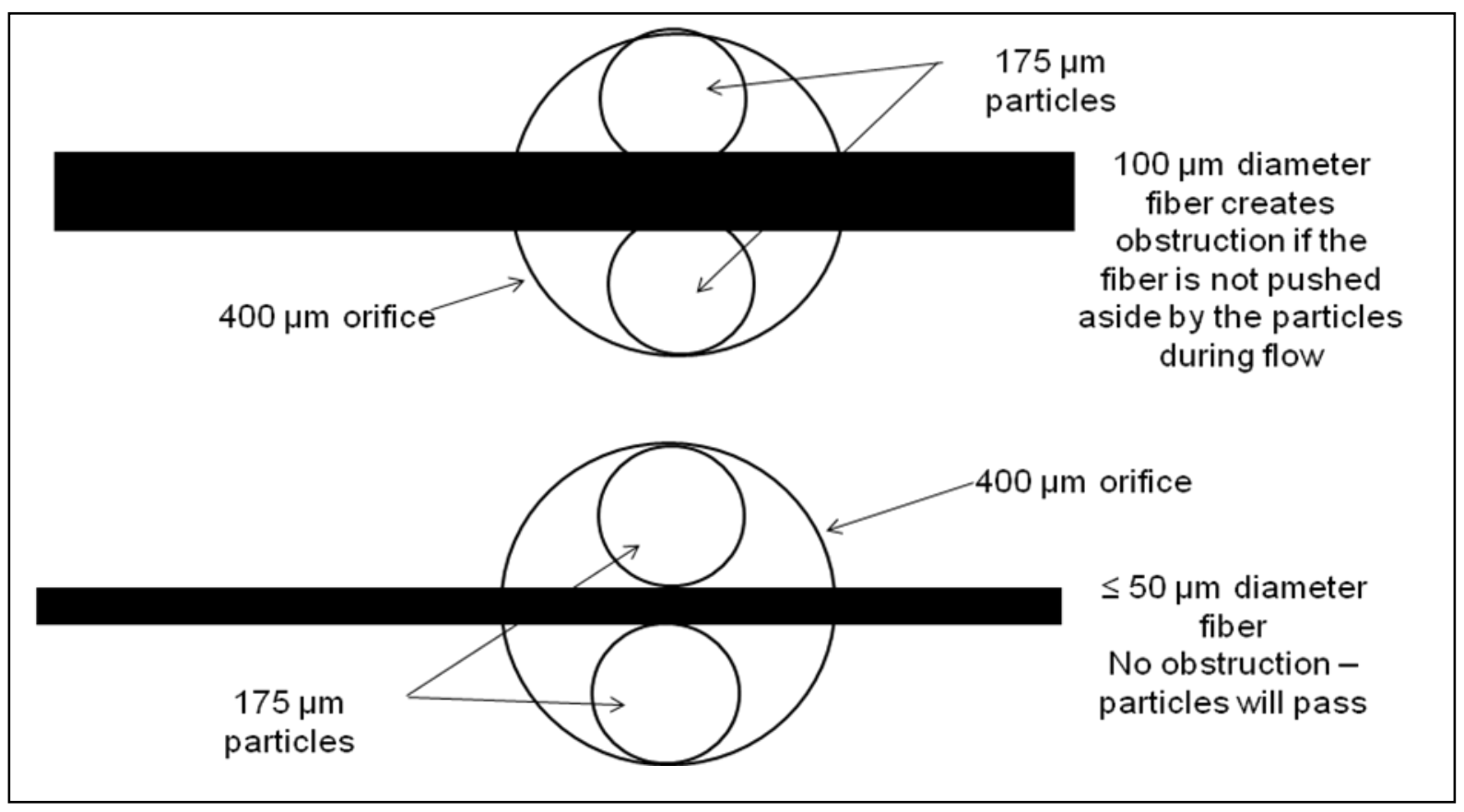

Figure 3 - Orifice obstruction by two particles and one fiber

The relative level of restriction of the orifice can be calculated for each combination of up to three particles or fibers using the two-dimensional shadow of each contaminant as the worst case. The area of the obscuring particles versus the area of the orifice yields an obstruction ratio. Figures 4, 5 and 6 show the various permutations of $50 \mu \mathrm{m}$ diameter fibers and $186 \mu \mathrm{m}$ diameter particles (the actual three ball limit) obscuring $400 \mu \mathrm{m}$ round and square orifices and their resulting obscuration ratios.

It can be seen in figure 5 that one $50 \mu \mathrm{m}$ fiber and two $186 \mu \mathrm{m}$ particles can cause obstruction of a square $400 \mu \mathrm{m}$ orifice if the fiber lands just right. Likewise, two fibers and one particle of these sizes, oriented just right, can cause obstruction of a circular $400 \mu \mathrm{m}$ orifice. The overlap is slight and, when multiplied with the low probability that the three contaminants will encounter the orifice simultaneously, the required orientation is highly improbable. Furthermore, the resulting obscuration ratio is lower in each case than obstruction by three particles.

It is assumed for the calculations shown in figures 4 though 6 that the fibers are straight. Fibers that are not straight will not line up side by side to obstruct flow. Twisted fibers would be unlikely to cause more flow restriction than straight fibers. 


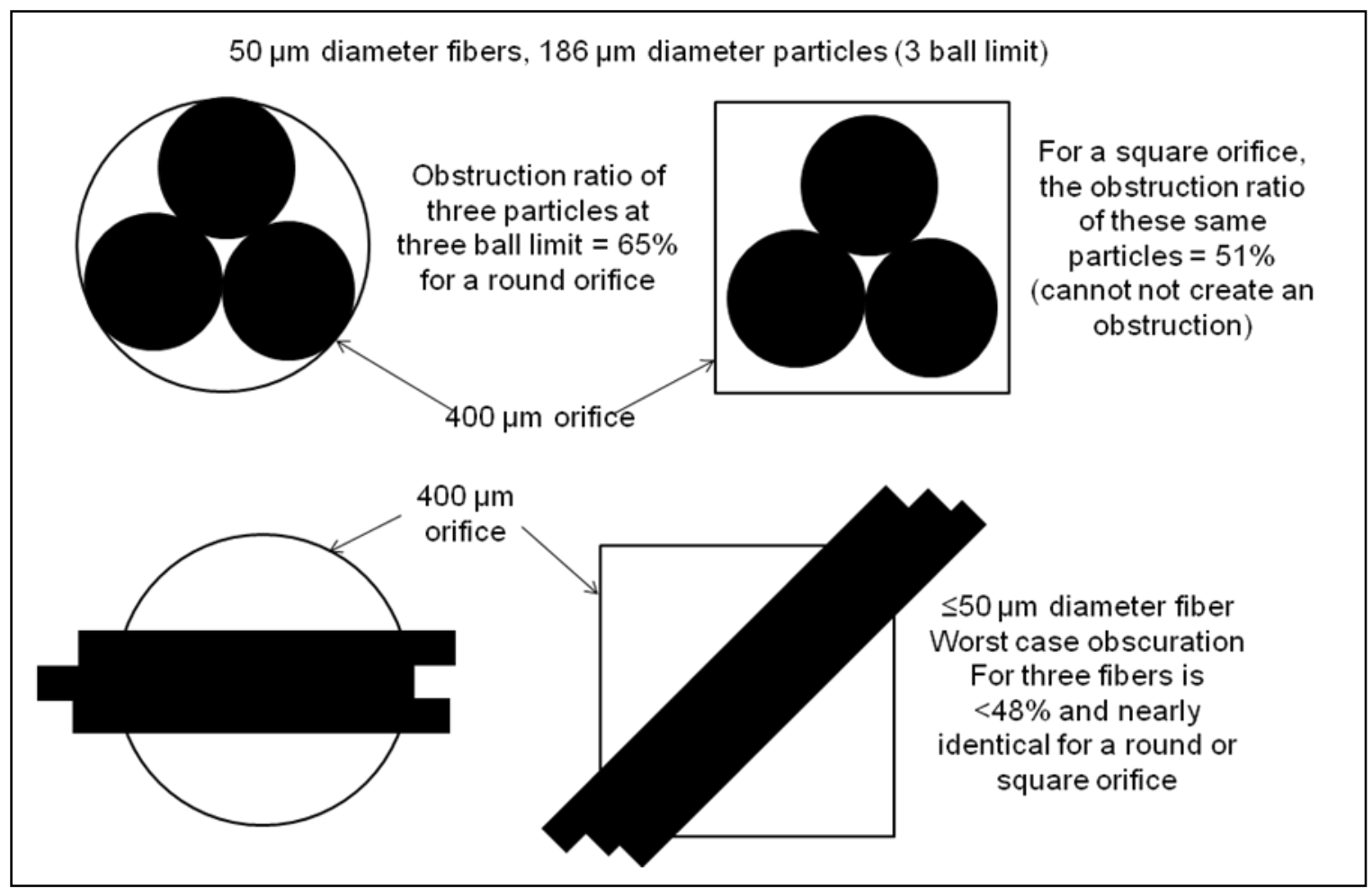

Figure 4 - Obstruction ratios of three round particles versus three parallel fibers

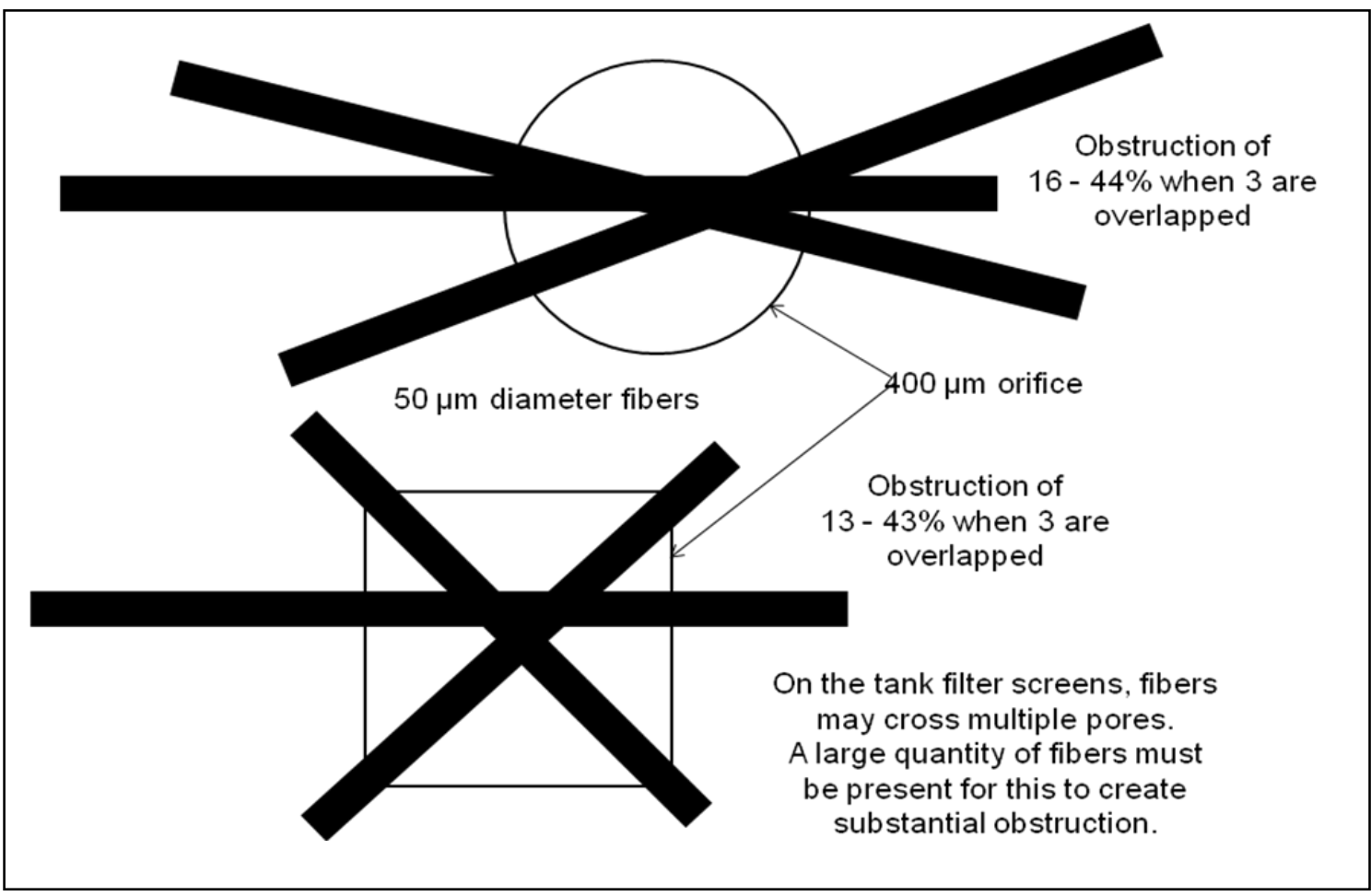

Figure 5 - Obstruction ratios resulting from overlapped fibers 


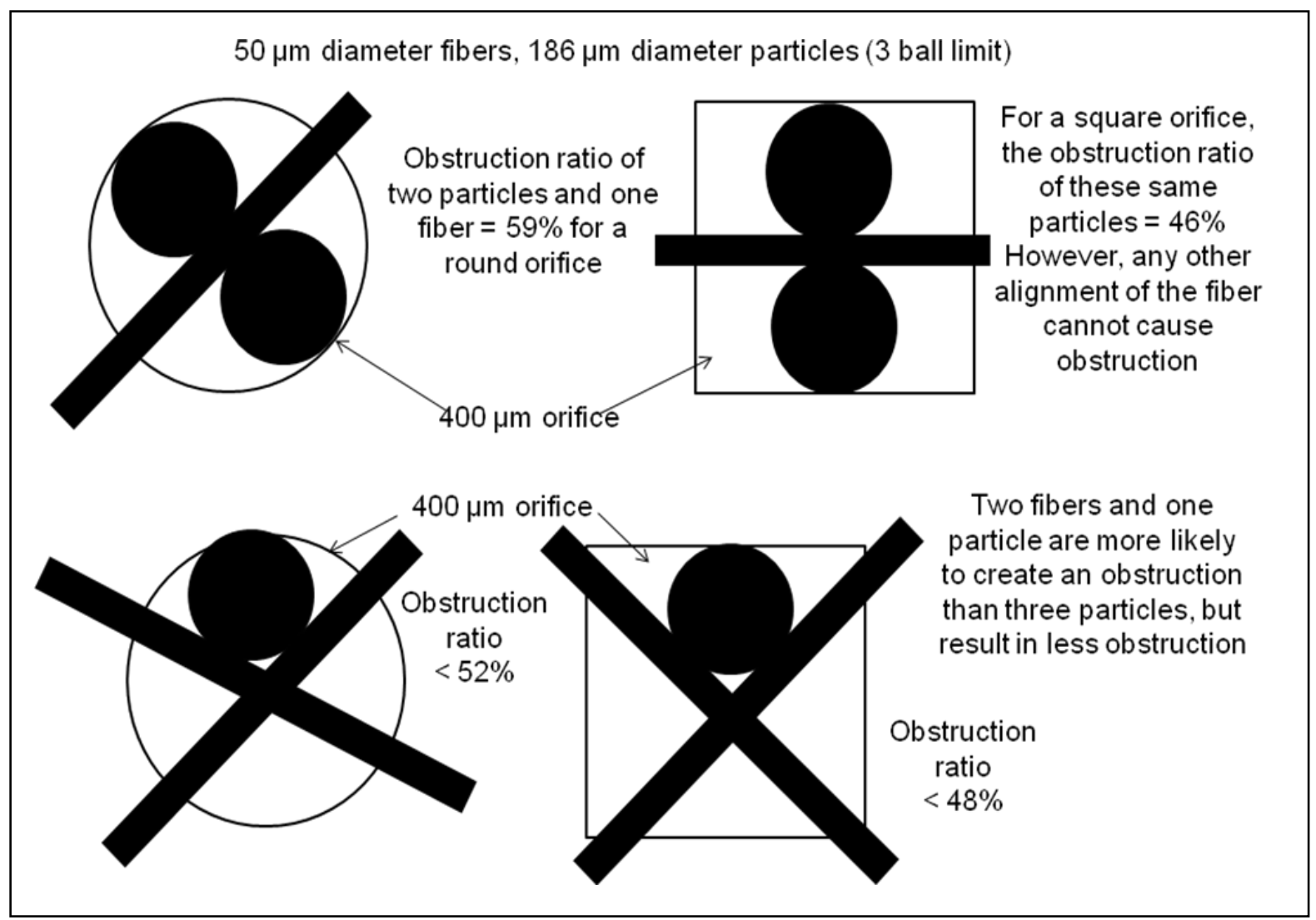

Figure 6 - Alternate contaminant orientations and their maximum obstruction ratios

\section{Conclusions based on critical orifice plugging or restriction}

Based on the above analyses, an unlimited number of fibers of a length less than or equal to the diameter of the critical downstream orifice size can be tolerated without reservation. Longer fibers, when limited to a maximum width of $50 \mu \mathrm{m}$ or less should be acceptable without risk in a system with a critical orifice size of $400 \mu \mathrm{m}$ or larger. A system with critical orifice size of 900 $\mu \mathrm{m}$ or larger should be able to tolerate fibers as wide as $100 \mu \mathrm{m}$ without obstruction.

These calculations do not point to a hard upper limit for length of fibers or quantity. To minimize the probability that rigid twisted fibers will create an obstruction within an orifice, the maximum length of fibers should be limited to less than 2.5 times the diameter of the downstream orifice. For MSFC-SPEC-164 Class III and Class IV, a conservative maximum length for fibers would be $2000 \mu \mathrm{m}$ and $1000 \mu \mathrm{m}$ respectively.

Without detailed knowledge of fluid system surface areas, filter designs, and filter locations internal to the downstream system, a maximum allocation for quantity of fibers cannot be determined. However, an allocation of two fibers per sample smaller than $50 \mu$ diameter $\mathrm{x}$ $1000 \mu \mathrm{m}$ long provides less surface area restriction than one particle $400 \mu \mathrm{m}$ in maximum dimension. Two fibers per sample smaller than $100 \mu \mathrm{m}$ diameter x $2000 \mu \mathrm{m}$ long provides less surface area restriction than one particle $800 \mu \mathrm{m}$ in maximum dimension. This would seem to be a conservative allocation. 
In the propellant tanks, long twisted fibers capable of being lodged in a critical orifice will be prevented from reaching the orifice by the tank filter screens. Straight fibers, however, when aligned with the direction of fluid flow, will bypass the tank filter. Fibers present in the tanks must also be restricted to the maximum diameter required for the downstream system.

None of the above scenarios require that the fibers be nonmetallic. Restrictions on fiber composition may be based on other potential failure mechanisms for a system.

Other potential failure mechanisms from particulate contamination than orifice plugging must also be considered. These include excessive restriction of system filters, valve seal leakage, and potential ignition of contaminants in LOX systems.

\section{Filter Face Obscuration Leading to Flow Restriction}

Scenarios 1-3 above assumed that particles will align with the flow and encounter the orifice lengthwise, generally passing though. Scenario 4 considered the potential for fibers or a combination of fibers and particles to block a critical orifice. The potential also exists for a quantity of fibers to accumulate on the filter face upstream of a critical orifice and restrict flow. To manage this risk, an allocation must be established for fibers to limit the potential restriction to an acceptable level.

To analyze the potential for particles or fibers to obscure a filter face to an unacceptable degree, the area of the filter face and the allowable restriction must be known. The total internal surface area upstream of the filter times the allocation of allowable particles per square foot determines the total contaminant load that is potentially available to travel downstream to the filter. When a particulate allocation, such as MSFC-SPEC-164 Table 1, has already been determined, it is possible to evaluate the relative restriction potential of fibers versus particles accumulated on a filter surface and equivalent allocations for fibers can be calculated.

Using the two dimensional area, or "shadow" of the particle as the measure of restriction potential for particles larger than the orifice size of the filter, relative restriction of particles versus fibers can be calculated. This is a simplification since particles and fibers are three dimensional and rarely appear as disks or ribbons. This simplification, however, is conservative because fluids will more easily flow around round, cylindrical, or irregular particles.

For the lowest fiber aspect ratio (by definition) of 10:1, the fiber length that equates to the shadow area of a round particle is calculated as follows:

$\begin{array}{lc}\text { Area of a fiber shadow: } & \mathrm{L} \times \mathrm{W}=\mathrm{L} \times \mathrm{L} / 10=\mathrm{L}^{2} / 10 \ldots \\ 2 & \pi \mathrm{r}^{2} \\ \text { Area of particle shadow: } & \downarrow \\ & \mathrm{L}^{2} / 10=\pi \mathrm{r}^{2} \\ \text { Equate these: } & \downarrow\end{array}$


Yields:

$$
\mathrm{L}=\sqrt{ }\left(\pi(\mathrm{D} / 2)^{2} \times 10\right)
$$

where $\mathrm{L}=$ the length of a fiber with aspect ratio $10: 1$ and $\mathrm{D}=$ the diameter of the particle

A 10:1 fiber with a length 2.8 times the diameter of the particle yields equivalent obscuration (shadow area).

Based on equivalent filter face obscuration, the lengths and quantities of fibers permitted for each class of particulate cleanliness in MSFC-SPEC-164 are shown in table 4. It should be noted that the larger fibers, if present at the 10:1 aspect ratio, would be clearly visible as debris.

Table 4 - MSFC-SPEC-164 classes with equivalent fiber lengths based on obscuration

\begin{tabular}{|c|c|c|c|c|c|}
\hline CLASS & $\begin{array}{l}\text { PARTICLE SIZE } \\
\text { IN MICRONS }\end{array}$ & $\begin{array}{l}\text { MAX. NUMBER } \\
\text { PER 0.1 m }\end{array}$ & $\begin{array}{c}\text { LENGTH OF } \\
\text { EQUIV. FIBER } \\
\text { AT 10:1 ASPECT } \\
\text { RATIO }\end{array}$ & 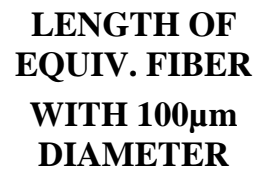 & 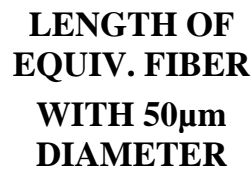 \\
\hline I & $\begin{array}{c}>2500 \\
700<\mathrm{x} \leq 2500 \\
175<\mathrm{x} \leq 700 \\
\text { NO SILTING } \\
\end{array}$ & $\begin{array}{l}0 \\
1 \\
5\end{array}$ & $\begin{array}{c}>7000 \\
1960<x \leq 7000 \\
490<x \leq 1960\end{array}$ & $\begin{array}{c}>49063 \\
3847<x \leq 49062 \\
240^{\mathrm{a}}<\mathrm{x} \leq 3847\end{array}$ & $\begin{array}{c}>98125 \\
7693<\mathrm{x} \leq 98125 \\
481^{\mathrm{a}}<\mathrm{x} \leq 7693\end{array}$ \\
\hline II & $\begin{array}{c}>1000 \\
700<\mathrm{x} \leq 1000 \\
175<\mathrm{x} \leq 700 \\
\text { NO SILTING }\end{array}$ & $\begin{array}{c}0 \\
40 \\
150\end{array}$ & $\begin{array}{c}>2800 \\
1960<x \leq 2800 \\
490<x \leq 1960\end{array}$ & $\begin{array}{c}>7850 \\
3847<x \leq 7850 \\
240^{\mathrm{a}}<\mathrm{x} \leq 3847\end{array}$ & $\begin{array}{c}>15700 \\
7693<x \leq 15700 \\
481^{\mathrm{a}}<\mathrm{x} \leq 7693\end{array}$ \\
\hline III & $\begin{array}{c}>800 \\
\text { NO SILTING }\end{array}$ & 0 & $>2240$ & $>5024$ & $>10048$ \\
\hline III X & $\begin{array}{c}>800 \\
175<x \leq 800 \\
\text { NO SILTING }\end{array}$ & $\begin{array}{l}0 \\
5\end{array}$ & $\begin{array}{c}>2240 \\
490<x \leq 2240\end{array}$ & $\begin{array}{c}>5024 \\
240^{a}<x \leq 5024\end{array}$ & $\begin{array}{c}>10048 \\
481^{\mathrm{a}}<\mathrm{x} \leq 10048\end{array}$ \\
\hline IV & $\begin{array}{c}>400 \\
\text { NO SILTING }\end{array}$ & 0 & $>1120$ & $>1256$ & $>2512$ \\
\hline IV X & $\begin{array}{c}>400 \\
175<x \leq 400 \\
\text { NO SILTING } \\
\end{array}$ & $\begin{array}{l}0 \\
5\end{array}$ & $\begin{array}{c}>1120 \\
490<x \leq 1120\end{array}$ & $\begin{array}{c}>1256 \\
240^{\mathrm{a}}<\mathrm{x} \leq 1256\end{array}$ & $\begin{array}{c}>2512 \\
481^{\mathrm{a}}<\mathrm{x} \leq 2512\end{array}$ \\
\hline $\mathrm{V}$ & ISUALLY CLEAI & O SILTING & & & \\
\hline
\end{tabular}

a. Does not meet the minimum 10:1 aspect ratio for a fiber

If fibers are limited to a diameter of $100 \mu \mathrm{m}$ or $50 \mu \mathrm{m}$ due to concerns over plugging of individual orifices downstream, then the fiber length that will create an equivalent level of obstruction versus a round particle becomes much longer for the larger particle sizes. This is 
shown in the two right columns of table 4. These thin fibers become absurdly long when equated to particles larger than $800 \mu \mathrm{m}$, with lengths better measured in centimeters than micrometers.

As shown in table 4, the allocation based on critical orifice plugging, for two fibers per square foot, at no larger than $50 \mu \mathrm{m}$ diameter (1/8 x diameter of the critical orifice) by $1000 \mu \mathrm{m}$ long (2.5 x diameter of the critical orifice) for Class IV and no larger than $100 \mu \mathrm{m}$ diameter by $2000 \mu \mathrm{m}$ long for Class III, yields less obscuration than one maximum size particle for those systems.

\section{Valve Seal Leakage}

A single particle of contamination, if sufficiently large and positioned on a sealing surface, can prevent a valve from fully closing, creating a leak path for propellants or pressurants. Abrasive particles in excessive quantities can also, over time, erode seats and seals resulting in leakage. Propulsion system valves and seals have allocations for allowable leakage.

It is difficult to calculate or predict the minimum size particle that will cause a valve to leak. Valve seals are designed to deform around minor surface variations and small contaminants to assure a good seal. This is true even for metal sealing surfaces in oxygen systems. These surfaces are composed of relatively soft metal alloys or metals coated with oxygen compatible nonmetal coatings that are slightly compliant.

The tolerance of valve seat coatings to leakage from hard particle contamination has been studied. A study performed by McDonnell Douglas Astronautics Company in 1975 for NASA Lewis Research Center tested the contamination tolerance of various nonmetallic coatings on valve seats. This study concluded that particles will be embedded in coatings of relatively hard plastic materials such as Xylon 1010, Kynar 202, and Teflon S, without resulting in leakage. While some particle deformation generally occurs during embedment, a coating thickness of 20$30 \%$ more than the largest anticipated particle diameter was recommended. Particles up to 420 $\mu \mathrm{m}$ were tested to verify leakage resistance. [16] Assuming that seals will crush very thin twisted fibers down to their diameter and deform around them, even metallic fibers limited to 50-100 $\mu \mathrm{m}$ in diameter should be of minimal concern.

Rodenbucher [12], documented several instances of excessive valve leakage in the Saturn SII stage LH2 systems where particulate contamination may have contributed to the failure. Forty one Problem Action Records (PARs) related to contamination were reported during the processing of fifteen S-II units at Seal Beach, the Mississippi Test Facility, and Kennedy Space Center. The failures due to contamination were primarily seal leakage above specification requirements, none of which would have resulted in a mission failure. This report recommended that particle contamination allocations be limited to only non-metallic particles and fibers above $175 \mu \mathrm{m}$, and only nonmetallic fibers above $700 \mu \mathrm{m}$. These two limits, considered together, imply a maximum width for fibers of $70 \mu \mathrm{m}$. The rationale for distinguishing between metallic and nonmetallic particles was not explained. While five specific instances were noted of leakage in LH2 prevalve solenoids due to metallic particles, the PAR history showed that approximately half of the contaminants identified as the cause of leakage were nonmetallic. The detailed particle analyses in this report did not distinguish between metallic particles and metallic fibers. 
It appears that if all fibers are restricted to a maximum diameter of $70 \mu \mathrm{m}$ then it is not necessary to distinguish between metallic and nonmetallic fibers.

It is conceivable that a large quantity of hard metallic fibers, even if restricted to below 70 $\mu \mathrm{m}$ in diameter, could abrade the surfaces of seals and pumps. Contamination by a large quantity of any type of small, hard particle, such as sand, could also cause such abrasion. The requirement in MSFC-SPEC-164 for "no silting” is expected to avoid this scenario.

A problem report on "Engine LOX Pump Contamination” on Saturn S-II-12 [17] identified metallic and nonmetallic fibers and shavings that were found during an engine modification not related to any failure. These particles included a stainless steel bristle .003 inches in diameter by 0.5 inches long (76 $\mu \mathrm{m}$ by 12,700 $\mu \mathrm{m})$, a Kel-F shaving .001 x .002 x 4 inches $(25 \mu \mathrm{m}$ x $51 \mu \mathrm{m} \times$ $10 \mathrm{~cm})$, a stainless steel fragment $.001 \times .005 \times .030$ inches $(25 \mu \mathrm{m} \times 127 \mu \mathrm{m} \times 762 \mu \mathrm{m})$, and a crescent of PCV (sic) .005 x 0.25 inches $(127 \mu \mathrm{m}$ x $6350 \mu \mathrm{m})$. During a subsequent inspection of the LOX pumps on Saturn S-II-13, a "5-1/2 inch long strand" $(14 \mathrm{~cm})$ of Kel-F with "irregular surfaces" was found in a LOX pump. Four of these five particles meet the definition of fiber. It was concluded in this report that none of these contaminants would be detrimental to stage performance and, beyond a source analysis to determine whether a component was chafing, no further action was recommended.

Other reports on Space Shuttle valve leakage noted the size of particle that appeared to be the cause of the leakage. One particle noted to cause leakage was a nitrile rubber particle $.146 \mathrm{x}$ $.046 \times$.018 in. (3700 x $1168 \times 457 \mu \mathrm{m}$ ) located on a poppet face. [18] This particle far exceeded the maximum allowed size of $800 \mu \mathrm{m}$ for the oxygen system.

Significant advances have been made in the understanding of seal design for cryogenic systems since the Saturn days. Given the known capabilities to design valves and sealing surfaces for these systems that will tolerate isolated particulate contaminants up to $400 \mu \mathrm{m}$ in LH2 systems and $800 \mu \mathrm{m}$ in LOX systems, the presence of occasional fibers that are limited in these systems to a maximum diameter of 50-100 $\mu \mathrm{m}$ should be of little consequence. Based on the Saturn S-II experience, a maximum fiber diameter of $70 \mu \mathrm{m}$ for all systems seems reasonable to prevent seal leakage. No rationale has been identified to support different allocations for nonmetallic versus metallic fibers when such a diameter restriction is imposed.

\section{Fire Hazards in Oxygen Systems}

Both organic and inorganic contaminants may present an ignition hazard in enriched oxygen systems. As noted in ASTM Manual 36, Safe Use of Oxygen and Oxygen Systems, [1] particle contaminants entrained in flowing oxygen may ignite on impact presenting an ignition hazard in high pressure or high velocity oxygen systems, particularly in poorly designed systems. Accumulations of organic matter such as oil films can be ignited by particle impact, rapid pressurization or other mechanisms. Acoustic resonance has also been shown to be capable of igniting an accumulation of particulate. Fibers to be permitted within an oxygen system must not present a greater ignition hazard than either an impacting particle or an accumulation of ignitable organic residue or particulate. 


\section{Particle Impact Ignition and the Kindling Chain}

Studies of the ignition of metals by impact of low velocity [13] and high velocity [19] particles have shown that ignition depends on both the kinetic energy of the particle at impact and the heat of combustion of the particle. The localized heat generated by this impact must be sufficient to ignite the material impacted in order to initiate a kindling chain. With the possible exception of aluminum targets impacted at high particle velocities, it appeared that ignition of the impacting particle was required in order to ignite the target. Higher system pressures, flow velocities, and oxygen temperatures increased the probability of ignition of the particle and target. It was also noted that although small particles were easier to ignite, a single large particle was more likely to ignite the target than a large quantity of smaller particles. [13]

Particle impact has been studied for high pressure gaseous oxygen systems at NASA's Johnson Space Center - White Sands Test Facility (WSTF). Studies of the conditions under which particle impact ignition of various target materials will occur in gaseous oxygen indicate that such ignition will not occur at LOX temperatures or at the relatively low pressures and velocities found in LOX propellant tanks and feed systems. However, higher transient temperatures and velocities may occur with the presence of GOX during system fill and cool down pre-flight where particulate impact ignition must be considered. Hundreds of successful tanking operations of the Space Shuttle and its associated GSE demonstrate that hazards are effectively controlled by particle limits of up to $1000 \mu \mathrm{m}$ in LOX propellant tanks (MSFCSPEC-164 Class II) and $800 \mu \mathrm{m}$ in LOX feed and drain systems and GOX vent systems.

An impacting fiber of the same composition and mass as an impacting particle should yield the same or lower kinetic energy and energy flux density. Benz, et. al., noted that deformation of the target or particle on impact will reduce the heat energy of the impact. [19] A small diameter metal fiber, that could be expected to deform on impact, may be less likely to ignite a target than a metal particle of comparable composition and mass. Based on the formulas for the volume of a sphere versus the volume of a cylinder, a fiber with the worst case aspect ratio of 10:1 will have a length of 3.75 times the diameter of a particle of the same material to yield the same impact mass. Based purely on the impact mass equivalent to a $1000 \mu \mathrm{m}$ or $800 \mu \mathrm{m}$ metallic particle, the maximum allowable metallic fiber length would be $3750 \mu \mathrm{m}$ in the tank and $3000 \mu \mathrm{m}$ in downstream oxygen systems. At the 10:1 aspect ratio, these fibers would be clearly visible as chips or shavings.

Most laboratory particle impact tests have used metal or oxide particles impacting metal targets. In 1995, a report was published by Dees, et al. on an evaluation of polymer particles as an ignition source in oxygen. [20] Particles of Teflon, Vespel SP-21, Kel-F 81, and Viton A were impacted against stainless steel targets. Both large (up to $2000 \mu \mathrm{m})$ and small $(250 \mu \mathrm{m})$ particles were tested at subsonic and supersonic velocities and a range of temperatures. No target ignitions were observed under any of the test conditions, including those known to ignite the target when the particle is metallic. In several cases, it was evident that the polymeric particle ignited but no ignition of the target occurred. It was theorized that the lower densities, lower yield strengths, and different burning characteristics of polymers result in lower kinetic energy and energy flux density transferred to the target than comparably sized metal particles. It has 
been generally accepted by the oxygen systems design community that "nonmetal particulate is not an effective igniter”. [1]

By comparing the volume and specific gravity of fibers versus metallic particles, maximum fiber sizes can be calculated that yield an equivalent impact mass. Using a round, $1000 \mu \mathrm{m}$ diameter steel particle of approximately $8 \mathrm{~g} / \mathrm{cm}^{3}$ as a worst case, the most massive particle permitted in the tank is $4.2 \mathrm{mg} ; 2.1 \mathrm{mg}$ in all other LOX system components.

The specific gravity of nonmetallic fibers ranges from $0.3 \mathrm{~g} / \mathrm{cm}^{3}$ for lightweight paper to 2.6 $\mathrm{g} / \mathrm{cm}^{3}$ for fiberglass. Carbon composite fibers fall around $2 \mathrm{~g} / \mathrm{cm}^{3}$. Clothing fibers range from $1.1 \mathrm{~g} / \mathrm{cm}^{3}$ for nylon to $1.5 \mathrm{~g} / \mathrm{cm}^{3}$ for cotton. Even using the specific gravity of fiberglass, which is inert and will not ignite, calculations based on equivalent particle mass yield absurdly large fibers of $4700 \mu \mathrm{m}$ (vs. an $800 \mu \mathrm{m}$ particle) and $9000 \mu \mathrm{m}$ (vs. a $1000 \mu \mathrm{m}$ particle) at the 10:1 aspect ratio. If the fibers are restricted to a diameter less than $100 \mu \mathrm{m}$, as indicated by the calculations for critical orifice plugging, the risk of a fiber of any composition causing an impact ignition based on mass becomes insignificant.

\section{Ignition of Accumulated Fiber Mass}

The potential for ignition of an accumulated mass of contaminants must also be considered when establishing an allocation for fibers. Fibers present within assembled fluid systems prior to system fill, if entrained in the fluid flow, will tend to accumulate on system filters if the fibers are longer than the filter orifice diameters. Wire mesh, used as filter media in oxygen systems, propagates combustion more readily than rods or plate of the same material. Testing has shown that stainless steel, low carbon steel, and Monel 400 will propagate combustion in oxygen at atmospheric pressures. [21]

Test methods have been developed to evaluate the suitability of filter designs and materials of construction for use in high pressure oxygen service. Recognizing that filters must continue to perform safely in the presence of contaminants, these tests used particles and oils as ignition promoters with adiabatic compression or particle impact as the ignition source. Barthelemy, et al., [22] used adiabatic compression to ignite oil, which then ignited $1 \mathrm{~g}$ of $44 \mu \mathrm{m} 97 \%$ iron powder (hydrogen reduced), which was then ingested into the filter. Odom, et al., [23] adapted ASTM G175, Standard Test Method for Evaluating the Ignition Sensitivity and Fault Tolerance of Oxygen Regulators Used for Medical and Emergency Applications, [24] to test the ignition resistance of contaminated stainless steel and brass filters in high pressure oxygen. The test contaminant was a mixture of aluminum powder and iron particles with a perfluorinated lubricant. Neither of these investigations tested fibers or particles alone, without an oil or lubricant, nor was sensitivity testing performed to determine the influence of different levels of contaminant on the combustion of the filter.

Sensitivity studies on the hazards of ignition of accumulated surface contaminants in oxygen systems have focused on NVR such as oils and greases in high pressure GOX systems. These contaminants, if present in sufficient quantity at high oxygen concentrations, can be ignited by adiabatic compression or particle impact and promote ignition of the substrate. 
Limits established in the industry for NVR in oxygen systems range from $1 \mathrm{mg} / 0.1 \mathrm{~m}^{2}$ in NASA LOX and GOX systems [1, 3, 6] to $47.5 \mathrm{mg} / 0.1 \mathrm{~m}^{2}$ in commercial oxygen systems. [2] [11] [25] MSFC-SPEC-164 permits NVR up to $5 \mathrm{mg} / 0.1 \mathrm{~m}^{2}$ in flight LOX tanks and in ground test systems operating below 5000 psig. Since 1994, MSFC-SPEC-164 has permitted NVR as high as $20 \mathrm{mg} / 0.1 \mathrm{~m}^{2}$, with approval of the Director of Safety, in ground test systems operating below 5000 psig.

If an allocation for fibers is established with a maximum size and a maximum quantity per square foot of surface area, then it is possible for this allowed background level of fiber to migrate and accumulate. The largest surface area where particulate could accumulate prior to being collected on a filter or ingested is within the LOX propellant tank of the main propulsion system. Assuming that fibers are present at the maximum size and quantity on all interior surfaces of the LOX tank and all of these fibers are swept to and collected on the tank sump filter face during system operation, then a worst case total accumulation on the filter can be calculated.

The allocation in the baseline release of MSFC-SPEC-164 for one particle up to $2500 \mu \mathrm{m}$ per square foot may have been intended to accommodate the occasional fiber. Using this limit as the proposed allocation for fibers in the LOX tank, a worst case total accumulation of fibers, 2500 $\mu \mathrm{m}$ long by $50 \mu \mathrm{m}$ diameter, is $<20 \mathrm{mg} / 0.1 \mathrm{~m}^{2}$, based on the following assumptions:

- A 0.43 meter (17 inch) diameter filter screen.

- Particles are evenly distributed on a tank internal surface area of approximately $372 \mathrm{~m}^{2}$ $\left(4000 \mathrm{ft}^{2}\right)$.

- Average fiber density is $1.6 \mathrm{~g} / \mathrm{cm}^{3}$ (the high end of common environmental fibers).

- $\quad$ Maximum fiber volume is $4.9 \times 10^{-6} \mathrm{~cm}^{3}$ (2500 $\mu \mathrm{m}$ long $\times 50 \mu \mathrm{m}$ diameter).

- All fibers from the tank surfaces become entrained in the flowing LOX during system operation and accumulate on the tank filter screen.

- The distribution of accumulated fibers on the filter screen is uniform.

- All fibers shorter than $800 \mu \mathrm{m}$ and most fibers shorter than $1000 \mu \mathrm{m}$, the diagonal measure of an $800 \mu \mathrm{m}$ square mesh orifice minus 10\% to account for the width of the fiber, will pass through the filter screen unhindered. Assuming that the internal engine filters are no more restrictive than the tank screen, these fibers will be ingested by the engine and burned with the propellants. No accumulation of these fibers will occur.

- Most or all of these fibers are nonmetallic. Metallic particles do not typically occur as fibers, and when they do, metal fibers $<50 \mu \mathrm{m}$ in diameter are not typically found in such long lengths. Reports of cleanliness inspection failures due to fibers during propulsion systems cleaning have been reported to be from clothing fibers or something similar. [12] 
Limiting the fiber length to $2000 \mu \mathrm{m}$ reduces this accumulation to $<16 \mathrm{mg} / 0.1 \mathrm{~m}^{2}$. Further limiting the maximum fiber size by limiting the maximum diameter to $40 \mu \mathrm{m}$ reduces this accumulation to $<10.3 \mathrm{mg} / 0.1 \mathrm{~m}^{2}$.

If the fibers are metallic, with a density of approximately $8 \mathrm{~g} / \mathrm{cm}^{2}$, then accumulation on the filter of $2500 \mu \mathrm{m}$ x $50 \mu \mathrm{m}$ fibers could reach $100 \mathrm{mg} / 0.1 \mathrm{~m}^{2}$.

All of these scenarios exceed the current MSFC-SPEC-164 NVR limit of $5 \mathrm{mg} / 0.1 \mathrm{~m}^{2}$ for LOX tanks. However, there are several mitigating factors to indicate that this level of accumulation on the filter is both highly unlikely to occur and, if it did, unlikely to ignite and initiate a kindling chain.

Mitigating Factors, Fiber Floating - Tests at MSFC in 2011 of the response of fibers of cotton, silk, linen, jute, wool, paper, polyester, nylon, and miscellaneous dryer lint in both liquid nitrogen and LOX showed that all of these fibers float to the surface of the cryogen during fill of the vessel and tend to form clumps there. ${ }^{3}$ It can be assumed that nonmetallic fibers present within the LOX tank and not adhered to the walls by another mechanism will float to the LOX surface during fill.

Fibers floating at the LOX/GOX interface are not in contact with a combustible substrate. Even if an ignition of these fibers was possible, the initiation of a kindling chain in this location is not credible. Furthermore, if the tank is drained and refilled prior to flight these fibers will most likely be swept out of the tank and captured in ground support equipment filters. Such LOX drain and refill cycles are not uncommon on the launch pad. Even if they are not removed in this manner, floating fibers can be expected to reach the tank screen only near the end of the stage burn, if at all; leaving almost no opportunity for a metallic particle entrained in the flow to impact and ignite the accumulated fiber in a location where a kindling chain could be initiated.

Metallic fibers are five times denser than nonmetallic environmental fibers. These fibers are not expected to float in the cryogen and therefore could potentially collect on the tank filter.

Mitigating Factors, Heat of Combustion - Heat of combustion data is used to evaluate the potential for a material, once ignited, to ignite surrounding materials. Materials with lower heats of combustion are preferred for oxygen service. [1] Tests of promoted combustion by ignition of contaminants on metal surfaces have been performed using hydrocarbon-based oil films known to ignite readily in high-pressure oxygen systems. [26] These oils, such as mineral oil and hydraulic oil, have high heats of combustion as compared to common environmental fibers. The heats of combustion of various materials that constitute fibers, oils, and other types of potential oxygen system contaminants are shown in Table 5.

\footnotetext{
${ }^{3}$ Internal reports, Lowrey, N., ESTSG-FY11-01112, An Evaluation of the Response of Nonmetallic Fibers to Cryogenic Exposure, August 2011, and Lowrey, N., ESTSG-FY12-00079, An Evaluation of the Response of Nonmetallic Fibers to Cryogenic Exposure Phase Two: Liquid Oxygen Exposure, November 2011, Jacobs ESTS Group, George C. Marshall Space Flight Center Science and Engineering Contract NNM-05AB50C.
} 
Table 5 - Heat of Combustion of Contaminants

\begin{tabular}{|c|c|}
\hline Material & Heat of Combustion (cal/g) \\
\hline Stainless Steels & $1850-2000^{a}$ \\
\hline Cotton fiber & $3,900^{\mathrm{b}} ; 4,000^{\mathrm{c}}$ \\
\hline Polyester resin & $4,300^{c}$ \\
\hline Wood, pine & $4,700^{c}$ \\
\hline Titanium $\left(\mathrm{TiO}_{2}\right)$ & $4711^{\mathrm{a}}$ \\
\hline Silicone grease, Dow Corning 7 & $4,800^{c}$ \\
\hline Wool fiber & $4,900^{\mathrm{b}} ; 6,350^{\mathrm{c}}$ \\
\hline Silicone & $5,400^{d}$ \\
\hline Polyester fiber & $5,700^{b}$ \\
\hline Aluminum $\left(\mathrm{Al}_{2} \mathrm{O}_{3}\right)$ & $7,425^{a}$ \\
\hline Carbon & $7,835^{c}$ \\
\hline Nylon fiber, Nylon 6/6 & $7,400-7,900^{\text {b, c }}$ \\
\hline Esters & $8,500-9,600^{d}$ \\
\hline Hydraulic oil, MIL-H-83282 & $9,800^{d}$ \\
\hline Hydraulic oil, MIL-H-5606 & $10,100^{d}$ \\
\hline Mineral Oil & $10,700-11,000^{c, d}$ \\
\hline
\end{tabular}

a. ASTM Manual 36-2 ${ }^{\text {nd }}$ Table 3-11 [1]

b. Fact Sheet - Flame Resistance of Wool, Commonwealth Scientific and Industrial Research Organization [27]

c. Lowrie, R [28] (contains a compilation of data from other sources)

d. Totten, G. [29]

The heats of combustion of common environmental fibers are $20 \%$ to $60 \%$ lower than the oils used to evaluate the risk of contaminant ignition in oxygen systems. Heats of combustion of metals found in oxygen systems are $25 \%$ to $80 \%$ less than these oils. This reduces the energy available to initiate a kindling chain.

Metallic fibers have comparable heats of combustion to nonmetallic fibers but are denser. If ignited, an accumulation of metallic fibers, particularly aluminum fibers, in a high pressure system theoretically could release sufficient energy to initiate a kindling chain. The threshold fiber mass required to create such a hazard is unknown. Ignition studies of multiple particles have been performed by injecting 2-3 grams of fine particles as small as $10 \mu \mathrm{m}$ into flowing gaseous oxygen upstream of a target. $[13,19]$ Lower masses were insufficient to ignite the target. This is a much greater mass than the predicted $100 \mathrm{mg} / 0.1 \mathrm{~m}^{2}$ of metallic particles. The study by Odom, et al., of promoted ignition of metallic filters used $350 \mathrm{mg}$ to $3.5 \mathrm{~g}$ of mixed aluminum 
and iron in a thin layer of lubricant as the contaminant promoter. [23] These ignition studies tested different scenarios than the ignition of fibers alone, accumulated on the target by another source.

Mitigating Factors, Low Temperature and Heat Removal - Within the LOX tank and feed system of a propulsion system, the temperature and pressure conditions are considerably lower than those used to evaluate the risk of ignition of contaminants in oxygen systems. While LOX is at a concentration equivalent to gaseous oxygen at a very high pressure, the temperature is much lower than found in gaseous oxygen systems. Assuming that fibers distributed within a LOX system will accumulate on a filter during fluid flow rather than float to the LOX surface, the cryogenic LOX flow will rapidly remove heat generated by a possible ignition of these fibers, inhibiting propagation. This risk mitigation in LOX systems is discussed by Lowrie [28], and is supported by other industry tests referenced there.

The hardware that must be ignited by burning fiber has also been cooled by the LOX to a very low temperature. The effect of target temperature on target ignition by an impacting particle was studied by Benz et.al. [19] In those studies, no ignition of the target was observed below about 390 degrees K. At lower system pressures, no ignition of the target was observed below about 500 degrees $\mathrm{K}$. The scenario where a particle might impact an accumulation of fibers on a filter is only credible during LOX flow when the filter (target) is at a very low temperature.

Mitigating Factors, Contaminant Geometry - Lowrie [28] also mentions the influence of geometric conditions on heat transfer of an ignited promoter to the other material. To initiate a kindling chain, the ignited contaminant must transfer sufficient heat flux to ignite the surface on which it resides. Most fiber materials have densities, discussed above, which are higher than mineral oils or hydraulic oils. The density of these oils is typically 0.7 to $0.8 \mathrm{~g} / \mathrm{cm}^{3}$. However, fibers do not accumulate in a continuous layer. The fibers that have the potential to accumulate on filter screens are very long and often twisted. Accumulations of fibers contain a considerable amount of free space that is expected to both dissipate heat to the LOX and reduce the physical contact between the fibers and the substrate, reducing heat transfer to the substrate material.

Furthermore, nonmetallic particles have been shown to be incapable of transferring sufficient heat flux to substrates during impact ignition to initiate a kindling chain. [1] The lower yield strengths and the burning characteristics of polymers that are theorized to contribute to lower kinetic energy and energy flux density transfer to the target during impact can also be expected to limit the transfer of heat flux from the ignition of an accumulation of nonmetallic fibers to the filter substrate.

Mitigating Factors, Conservative Nature of the Existing NVR Limit - The technical basis for the $5 \mathrm{mg} / 0.1 \mathrm{~m}^{2}$ limit for NVR in LOX tanks [3] has not been identified. It has been suggested that this NVR limit was the best that could be achieved and verified at that time on such a large surface area. More recent testing has shown that hydrocarbon-based oils could be ignited in gaseous oxygen by rapid pressurization at levels as low as $6 \mathrm{mg} / 0.1 \mathrm{~m}^{2}\left(65 \mathrm{mg} / \mathrm{m}^{2}\right)$. [26] However, this reference also reported that none of the ignitions observed during testing, even at the very high NVR levels of $300 \mathrm{mg} / 0.1 \mathrm{~m}^{2}\left(3200 \mathrm{mg} / \mathrm{m}^{2}\right)$, led to an ignition of the 
stainless steel tube used as the test article. The author cautioned that other substrate materials, such as non-metals, may ignite under these conditions.

Werley [30] summarized oil film ignition data from a number of earlier sources. One of the quoted NASA sources (Bryan, C. J., "Final Report on the Effect of Surface Contamination on LOX Sensitivity”, NASA-KSC Letter Report MTB 306-71, 1971 ${ }^{4}$ ) stated surface contamination limits for Dow Corning 704 silicone oil (a highly reactive oil) that resulted in reaction of a substrate during liquid oxygen mechanical impact tests at $98 \mathrm{~N}-\mathrm{m}$ of energy. This source reported no reactions on aluminum 6061-T6 below $43.2 \mathrm{mg} / 0.1 \mathrm{~m}^{2}$ and no reactions on Teflon below $21.6 \mathrm{mg} / 0.1 \mathrm{~m}^{2}$.

These reports indicate that the NVR limit of $5 \mathrm{mg} / 0.1 \mathrm{~m}^{2}$ in LOX tanks is very conservative. If fiber accumulation can be compared to NVR as an ignition promoter, then ignition of aluminum and stainless steel tank filter screens by fibers at accumulated levels equal to or below $20 \mathrm{mg} / 0.1 \mathrm{~m}^{2}$ is highly unlikely.

Mitigating Factors, No Credible Ignition Mechanism - For a fire to occur in the LOX tank there must be a credible ignition mechanism. ASTM Manual 36- ${ }^{\text {nd }}$ lists twelve ignition mechanisms that have been known to cause fires in oxygen systems. They are: particle impact, heat of compression from rapid pressurization, flow friction, mechanical impact, friction, fresh metal exposure, static discharge, electrical arc, chemical reaction, thermal runaway, resonance, and external heat. [1] Some of these mechanisms are poorly understood and this list of mechanisms may not be complete.

As noted above, particle impact does not appear to be a credible ignition source in LOX. GOX will be present at the expected fiber accumulation location, the tank filter screen, during the beginning of the fill of the LOX tank as boil-off from the LOX. Fluid velocity is insufficient at this time to support a particle impact risk. The LOX tank is purged with nitrogen prior to LOX fill.

Rapid pressurization and resonance sufficient to ignite contaminants are not credible within the large volume of the LOX tank. No materials are present that react chemically or exothermally in LOX or ambient temperature GOX. The LOX tank filter screen assembly contains no moving parts to generate friction heat. Static discharge, electrical arc, and external heat are precluded by design and operational precautions as a general safety measure.

Current theory indicates that flow friction can occur above $3.4 \mathrm{MPa}$ (500 psi), which is several times the maximum design pressure of reviewed LOX tank seals and feed line designs and more than ten times ambient service pressures. Also, heat generated by friction during LOX flow will immediately be dissipated by the flowing cryogenic fluid.

Mechanical impact ignition with fresh metal exposure could potentially occur from a large foreign object falling onto the LOX tank skin or filter screen. This would need to occur at the beginning of LOX tank fill before sufficient LOX is present to buoy the falling object and dampen the impact energy. Foreign Object Debris (FOD) prevention measures are used

\footnotetext{
${ }^{4}$ A copy of this secondary source has not been located.
} 
throughout vehicle processing to eliminate FOD. A LOX/LH2 vehicle stage also undergoes several rotations and moves between horizontal and vertical prior to a LOX fill. A loose item of sufficient mass to cause ignition escaping notice prior to LOX fill and dropping at just the right time is highly unlikely.

Conclusions on the Ignition Risk of Accumulated Fiber in a LOX Tank - The potential exists for fibers, present at the maximum allocation based on critical orifice plugging and filter restriction, to accumulate on the LOX tank filter screen during system operation to a level that exceeds the $5 \mathrm{mg} / 0.1 \mathrm{~m}^{2} \mathrm{NVR}$ limit in the tank. If one fiber up to $50 \mu \mathrm{m}$ in diameter and 2500 $\mu \mathrm{m}$ in length is permitted per square foot of tank surface area, fiber accumulation on the filter screen could be as high as $20 \mathrm{mg} / 0.1 \mathrm{~m}^{2}$ (nonmetallic) or $100 \mathrm{mg} / 0.1 \mathrm{~m}^{2}$ (metallic). The significant number of mitigating factors, however, indicates that is not a credible fire risk,

It should be noted that this analysis assumes an even initial distribution of fibers throughout the tank. Given that environmental fibers have the tendency to entangle and form clumps that may lead to measurement error on large components, accumulations of fibers that are visible during inspections should not be permitted. It should also be noted that nonmetallic fiber contamination originating from clothing or from the outdoor environment are both more likely to occur and more difficult to control than metallic fiber contamination. Detection of more than an occasional metallic particle or fiber within a flight system is a potential indication of hardware damage or defect and should trigger a source investigation.

Ignition of Accumulated Fiber in other LOX System Components - It is assumed that most fiber contaminants that pass through the LOX tank filter screen will also pass through downstream filters and orifices, to be eventually ingested and burned by the engine. The fiber mass that is available to be accumulated on a filter is mainly dependent on the internal surface area between the upstream filter and the downstream collection point.

The largest downstream surface area in a propulsion LOX system is typically the oxidizer feed line. With a LOX tank mounted above the LH2 tank, the feed system on a large scale launch vehicle could be $46 \mathrm{~m}(150 \mathrm{ft})$. Multiplied by the circumference of a feed line diameter of $0.3-0.5 \mathrm{~m}^{2}(1-1.5 \mathrm{ft})$, the estimated internal surface area is $46-70 \mathrm{~m}^{2}\left(500-750 \mathrm{ft}^{2}\right)$; one fifth to one eighth the surface area of the tank. Potential fiber accumulation is reduced proportionally, to roughly $4 \mathrm{mg} / 0.1 \mathrm{~m}^{2}$ of nonmetallic or $20 \mathrm{mg} / 0.1 \mathrm{~m}^{2}$ of metallic fiber. This assumes a single feed line with end point distribution to several engines.

LOX feed system components are expected to have maximum design pressures under 125 psia with nominal operating pressures under 50 psia and low flow velocities compared to GOX systems. Given these operating conditions and a lower potential accumulation, the fiber limits allocated for the LOX tank should be acceptable for downstream LOX components as well. However, a system analysis should be performed to verify that transient high pressure or high temperature GOX will not occur in regions of the LOX components where fiber accumulation may occur.

Ignition of Accumulated Fiber in GOX System Components - The potential risk of promoted combustion from accumulated fiber contamination in locations where GOX may be present is 
less clear. While substantial test data is available regarding the risks of particle impact ignition of metal and nonmetal substrates, no test data on accumulated particulate or fibers as an ignition promoter has been identified. Colson, et al., [31] have reported fires in oxygen system filters under conditions of high velocity, particle impact, and excessive contamination. Monitoring of pressure drop and maintenance at regular intervals is recommended for all industrial oxygen systems. While Colson notes that particles, dust, and debris trapped on filters can ignite when ignition conditions are met, very little data is available to establish safe thresholds for maximum accumulation, dependant on particle or fiber size and system parameters such as pressure, velocity, temperature, and configuration.

Fano, et al., [32] noted that the auto-ignition temperatures of metals in powder form are much lower than in bulk materials, and that smaller particles may ignite larger particles which may in turn ignite bulk materials. However, this and other sources have indicated that to initiate a kindling chain, the particle(s) must be ignited prior to impacting the target. [13] Particle ignition in tests reported by Williams, et al., [13] did not occur at velocities less than $45 \mathrm{~m} / \mathrm{s}$, independent of pressure between 2 and $30 \mathrm{MPa}$. These conditions are much higher than typically found in liquid oxygen propulsion systems upstream of the engine and are not found in the tanks.

Within propulsion system components where GOX is present at temperature, pressure, and velocity conditions known to ignite particulate, accumulated metallic fiber could potentially serve as an ignition promoter. It seems unlikely that nonmetallic fibers limited to less than one fiber per $0.1 \mathrm{~m}^{2}$, with a maximum dimension of $50 \mu \mathrm{m}$ diameter by $2500 \mu \mathrm{m}$ long, could provide a sufficient accumulated combustion mass to create a hazard.

Conclusions on Fibers as Fire Hazards in Oxygen Systems - When fiber size is limited to below $50 \mu \mathrm{m}$ in diameter and quantities are limited by the "no silting" rule to prevent gross presence in the flowing oxygen, fibers of any composition do not present a significant impact ignition hazard. When total quantity, size, and visible accumulations are further restricted to limit accumulation on filters, the credibility of fibers creating a fire hazard by impact ignition is low.

An allocation for fibers in LOX tanks and downstream LOX components, when limited to 1 fiber/ $0.1 \mathrm{~m}^{2}$ with maximum dimensions of $50 \mu \mathrm{m}$ dia. and $2500 \mu \mathrm{m}$ long, does not appear to present a credible fire risk. There does not appear to be any rationale to require a distinction between metallic and nonmetallic fibers. However, the LOX system design should be analyzed to verify that transient GOX will not occur under temperature, pressure and velocity conditions sufficient to ignite a stray particle contaminant that might ignite an accumulation of metallic fiber.

Insufficient data is available to fully assess the potential fire risk from the ignition of an accumulation of metallic fibers within a GOX system, such as an oxidizer tank repressurization system, under high temperature, pressure, or velocity conditions. Limited testing by Odom, et. al., has shown that accumulated metallic particulate may contribute to ignition of stainless steel filter media in gaseous oxygen even under standard atmospheric pressures. 


\section{Conclusions}

There are numerous precedents in NASA and commercial documents and specifications for the allocation of fiber limits as a discrete particle type in LOX/LH2 bipropellant systems. Fiber limits specified elsewhere are consistent with the limits derived by this analysis.

\section{Fiber Size and Quantity Limits}

Based on the analyzed risk scenarios, fiber length limits larger than the established particle size limits should be permissible in LOX/LH2 propulsion systems and associated ground support equipment and test systems. Several of these scenarios require that a maximum allocation be established for fiber size and quantity.

To minimize the risk of orifice plugging in LH2 systems, prevent leakage of valve seals, and minimize the risk of accumulated combustible mass in LOX tanks, a maximum fiber width of 50 $\mu \mathrm{m}$ is advisable in both systems. With this width restriction imposed, it does not appear to be necessary to distinguish between metallic and nonmetallic fibers in the fuel system or in the LOX tanks. In regions of an oxygen system where GOX may be present, an analysis of pressure, temperature, and flow velocity conditions, including transients, should be performed at potential accumulation points to determine whether fibers can be tolerated.

In addition to this maximum fiber diameter of $50 \mu \mathrm{m}$, maximum allowable fiber length should be 2.5 time the critical orifice diameter. This is based on plugging of a critical orifice by a combination of a twisted fiber and particles.

These calculations do not point to a quantity limit for fibers with lengths between the maximum particle diameter and the maximum fiber length. However, some limit is necessary to limit the risk of filter restriction from an accumulation of these smaller fibers. The limits established in MSFC-SPEC-164 Classes I, IIIX, and IVX of not more than 5 particles between $175 \mu \mathrm{m}$ and the higher limit, applied to these intermediate length fibers, should provide an equivalent level of protection from flow restriction.

The maximum fiber size and quantity in the LOX system downstream of the tank filter is driven by both oxygen system safety concerns and plugging of a critical orifice in the engine by a combination of a twisted fiber and particles. Limiting all fibers to a maximum diameter of 50 $\mu \mathrm{m}$ and a maximum length of $2000 \mu \mathrm{m}$ will minimize the risk of critical orifice plugging.

The original MSFC-SPEC-164 limit of one particle up to $2500 \mu \mathrm{m}$, when restricted to fibers as recommended by Rodebacher, [12] appears to be a reasonable limit for both the LH2 and LOX tanks. In the LH2 tanks, this limit is driven by filter screen restriction. In the LOX tanks, this is driven by a prudent approach to limit the opportunity for accumulation of potentially combustible matter on the filter screen. Prohibitions on silting and visible accumulations of fiber also limit the potential for a combustible accumulation of fibers. 


\section{Restrictions for Fiber Composition}

Cleanliness specifications that require the inspector to distinguish between metallic and nonmetallic fibers, or between flexible and non-flexible fibers as a proxy for metallic versus nonmetallic, create difficulties in the inspection process. Trained microscopists can determine whether a fiber appears to be metallic based on apparent reflectivity or a silvery appearance, or flexible based on an apparent twisting of the fiber, but these distinctions are subjective. Definitive identification of metallic fibers versus nonmetallic fibers requires chemical analysis using expensive analytical methods such as scanning electron microscopy with energy-dispersive $\mathrm{x}$-ray spectroscopy. Cleanliness specifications that require identification of contaminant composition should be avoided if possible.

The analyses for fiber size and allocation based on orifice plugging, filter restriction, and valve seal leakage do not require a distinction between metallic and nonmetallic fibers when fiber diameter is limited to $50 \mu \mathrm{m}$. These are the only considerations that apply to the fuel system; therefore there is no need to distinguish between metallic and nonmetallic fibers in LH2 systems and associated pressurization or pneumatic systems that do not interface with oxygen systems.

Industry test data has shown that metallic particles pose an impact ignition hazard in high pressure, high velocity oxygen systems whereas nonmetallic particles do not. Limitation of all fibers to a maximum diameter of $50 \mu \mathrm{m}$ and maximum length of 2000 to $2500 \mu \mathrm{m}$ effectively limits mass such that individual metallic fibers cannot cause an impact ignition. Ignition of a limited accumulation of metallic or nonmetallic fibers inside a LOX tank appears highly unlikely due to the very low temperature, low tank pressure, relatively low velocities of potential impinging particles, and general absence of credible ignition sources. The relative risk of ignition in GOX of an accumulation of metallic versus nonmetallic fibers, where a credible ignition source may exist, is not clear. Allocations for any type of fiber that may permit accumulation in GOX systems must be approached with caution.

\section{Measurement of Fibers}

A specification that limits fiber size and quantity distinct from particles begs the question of how to measure the fiber. A circular cross section is assumed; therefore two measurements are required for each fiber, the apparent diameter and the length of the fiber at full extension. Both manual and automated methods of sizing and counting particles have limitations when applied to fibers.

Automated Measurement by Light Scattering - Automated devices that detect light scattering from particles are available for measurement in air, in liquids, and on surfaces. These devices can accurately count large quantities of particles within defined size bins but do not discern morphology or composition. These devices do not distinguish fibers from particles. Fiber size limits larger than the allowed particle size limits should not be permitted when using these devices as the sole measurement technique. 
Automated Image Analysis - Image analysis systems are used for sizing and counting of particles collected on a filter or a reference surface such as a fallout plate. Some sophisticated image analysis systems are capable of distinguishing between particles and fibers and sizing both types provided that the fibers are not overlapping. Automated image analysis may be used when combined with human observation of the counted images to verify that fibers in the field of view have been accurately interpreted by the automated system.

Microscopic Analysis - A microscopist trained in the counting and sizing of particles can readily distinguish between particles and fibers and can easily measure the apparent diameter of fibers and the length of straight fibers. Measurement of twisted fibers is more complex. Length can be approximated by measuring the fiber in segments or more accurately by using an opisometer on a calibrated image of the fiber displayed on a computer screen. Either method should be sufficiently accurate for verification.

Fibers that are electrostatically charged or very twisted may stand away from the measurement surface making them difficult to measure. Wetting of the background surface may help to flatten the fiber to the surface for easier measurement, neutralize the static charge, and prevent loss of the fiber sample to local air currents.

\section{Recommendations for Further Study}

To understand the potential for accumulated fiber to act as an ignition promoter, testing is recommended. Both metallic and nonmetallic fibers in the range of 20 to $50 \mu \mathrm{m}$ in diameter should be studied in concentrations of $20 \mathrm{mg} / 0.1 \mathrm{~m}^{2}$ to $300 \mathrm{mg} / 0.1 \mathrm{~m}^{2}$ on a test filter. Metal fibers tested should be composed of alloys used in the construction of propulsion system components. Nonmetallic fibers tested should be composed of common facility contaminants such as clothing fibers, paper and cardboard fibers, and carbon fibers used in the production of composites. Because NVR contamination is a known ignition promoter in oxygen systems, the potential synergistic effects of a combination of accumulated fibers and credible NVR levels should also be studied.

Tests should be performed to determine whether accumulated fiber lowers the threshold at which an understood ignition mechanism will ignite a target. Flight oxygen system filter materials should be the primary focus of this investigation. The test equipment and procedures used by Pedley, et. al. [26], to evaluate NVR contaminants as an ignition promoter or used by Odom, et. al. [23], to study filter design may be adapted to study this phenomenon.

\section{Acknowledgments}

The author wishes to thank the following members of ASTM International, Committee G04 on Flammability and Compatibility of Materials in Oxygen Enriched Atmospheres, for their input regarding the list of potential risks of fiber contaminants in enriched oxygen systems: Eddie Davis (NASA-MSFC); Susana Harper, Stephen Peralta, Christine Pina-Arpin, and Joel Stotlzfus (NASA-WSTF); Kyle Sparks (NASA-WSTF/Jacobs Technology, Inc); and Dr. Theodore Steinberg (Queensland University of Technology, Australia). 


\section{References}

[1] ASTM MNL36-2nd, Safe Use of Oxygen and Oxygen Systems: Handbook for Design, Operation, and Maintenance: 2nd Edition, H.D. Beeson, S.R. Smith, and W.F. Stewart, Eds., ASTM International, West Conshohocken, PA, 2007, <http://www.astm.org>.

[2] ASTM G93-03 (Reapproved 2011), Standard Practice for Cleaning Methods and Cleanliness Levels for Material and Equipment Used in Oxygen-Enriched Environments, ASTM International, West Conshohocken, PA, 2011, <http://www.astm.org>.

[3] MSFC-SPEC-164 Revision D, Cleanliness of Components for Use in Oxygen, Fuel, and Pneumatic Systems, Specification for, NASA Marshall Space Flight Center, Huntsville, AL, March 1, 2010, available online at https://standards.nasa.gov/documents/msfc.

[4] SAE AS598, Aerospace Microscopic Sizing and Counting of Particulate Contamination for Fluid Power Systems, SAE International, 2012, http://www.sae.org.

[5] SAE ARP1176 (Issued 1999-03, Reaffirmed 2009-11) Oxygen System and Component Cleaning and Packaging, Society of Automotive Engineers, Inc., 2009, http://www.sae.org.

[6] JSC SE-S-0073 Revision H, Space Shuttle Fluid Procurement and Use Control Specification, NASA - Johnson Space Center, June 18, 2007.

[7] GLM-QS-1700.1, Glenn Research Center, Safety Manual, Chapter 5, Oxygen, December 19, 2012, available online at http://smad-ext.grc.nasa.gov/shed/pub/gsm/gsm-manual.pdf.

[8] Bankaitis, H. and Schueller C.F., NASA SP-3072 (N73-15155), ASRDI Oxygen Technology Survey Volume II: Cleaning Requirements, Procedures, and Verification Techniques, Aerospace Research and Data Institute, Lewis Research Center, Cleveland, $\mathrm{OH}$, 1972.

[9] KSC-C-123 Revision J, Surface Cleanliness of Ground Support Equipment Fluid Systems, Specification for, NASA Kennedy Space Center, July 17, 2009, available online at https://standards.nasa.gov/documents/ksc.

[10] MSFC-SPEC-164 Revision B, Cleanliness of Components for Use in Oxygen, Fuel, and Pneumatic Systems, Specification for, Section 7 Appendix, NASA George C. Marshall Space Flight Center, November, 1994.

[11] CGA G-4.1-2009: Cleaning Equipment for Oxygen Service Sixth Edition, Compressed Gas Association, Inc., Chantilly, VA, 2009, www.cganet.com.

[12] Rodenbucher, P. G., SD 70-557-5, Saturn S-II Quality Assurance Techniques, Critical Process Control, Volume V - Contamination, Space Division of North American Rockwell Corporation, Seal Beach, CA, Oct. 30, 1970. 
[13] Williams, R. E., Benz, F. J., and McIlroy, K., "Ignition of Steel Alloys by Impact of Low-Velocity Iron/Inert Particles in Gaseous Oxygen”, Flammability and Sensitivity of Materials in Oxygen-Enriched Atmospheres, ASTM STP 986, D. W. Schroll, Ed., American Society for Testing and Materials, Philadelphia, 1988, pp. 72-84.

[14] IEST-STD-CC1246E: Product Cleanliness Levels - Applications, Requirements, and Determination, The Institute of Environmental Sciences and Technology, Arlington Heights, IL, February, 2013, http://www.iest.org.

[15] A table of the best known packings of equal circles in a circle, complete up to $\mathrm{N}=1100$, with references for the sources of the data, is found at http://hydra.nat.unimagdeburg.de/packing/cci/cci.html, copyright E. Specht, Nov. 8, 2011, last viewed May 13, 2015. This data can also be accessed at http://www.packomania.com.

[16] Endicott, D. L., NASA CR-134877, Valve Contamination Avoidance Devices Final Report, McDonnell Douglas Astronautics Co., May 1974 - July 1975. Available online at http://ntrs.nasa.gov.

[17] SD 72-SA-0158, Saturn S-II Stage Pre-Flight Areas of Concern Review Final Report, Space Division of North American Rockwell, 1972.

[18] Wood, B. K., NASA-CR-193830, RSS-8898, STS-55 Pad Abort Engine 2011 Oxidizer Preburner Augmented Spark Igniter Check Valve Leak, Rockwell International, March 22, 1993. Available online at http://ntrs.nasa.gov.

[19] Benz, F.J., Williams, R.E., and Armstrong, D., "Ignition of Metals and Alloys by HighVelocity Particles”, Flammability and Sensitivity of Materials in Oxygen-Enriched Atmospheres, ASTM STP 910, M. A. Benning, Ed., American Society for Testing and Materials, Philadelphia, 1986, pp. 16-37.

[20] Dees, J., Forsyth, E., Gunaji, M., and Stoltzfus, J. M., “An Evaluation of Polymers as Ignition Sources during Particle Impact in Oxygen”, Flammability and Sensitivity of Materials in Oxygen-Enriched Atmospheres, ASTM STP 1267, Janoff, D., et.al., Eds., American Society for Testing and Materials, Philadelphia, 1995, pp. 143-151.

[21] Stoltzfus, J. M., Lowrie, R. and Gunaji, M. V., "Burn Propagation Behavior of Wire Mesh Made from Several Alloys”, Flammability and Sensitivity of Materials in OxygenEnriched Atmospheres: Fifth Volume, ASTM STP 1111, J. M. Stoltzfus and K. McIlroy, eds., American Society for Testing and Materials, 1991, pp. 326-337.

[22] Barthelemy, H., Roy, D., and Schaaf, J.-P., "Filters for Use in High Pressure Oxygen Service - Qualification and Test Methods”, Flammability and Sensitivity of Materials in OxygenEnriched Atmospheres: Tenth Volume, ASTM STP 1454, T. A. Steinberg, H. D. Beeson, and B. E. Newton, Eds., American Society for Testing and Materials, 2003, pp. 69-74. 
[23] Odom, G. A., Chiffoleau, G. J. A., Newton, B. E., and Fielding, J. R., Promoted Ignition Testing of Metallic Filters in High-Pressure Oxygen, J. ASTM Intl., Vol. 6, No. 8, 2009. Paper ID JAI102300, available online at www.astm.org.

[24] ASTM G175-03 (R2011): Standard Test Method for Evaluating the Ignition Sensitivity and Fault Tolerance of Oxygen Regulators Used for Medical and Emergency Applications, ASTM International, West Conshohocken, PA, 2011, www.astm.org.

[25] NFPA 53: Recommended Practice on Materials, Equipment, and Systems Used in Oxygen Enriched Atmospheres, National Fire Protection Association, Quincy, MA, 2011 Edition.

[26] Pedley, M. D., Pao, J., Bamford, L., Williams, R. E., and Plante, B., "Ignition of Contaminants by Impact of High Pressure Oxygen”, Flammability and Sensitivity of Materials in Oxygen-Enriched Atmospheres, ASTM STP 986, D. W. Schroll, Ed., American Society for Testing and Materials, Philadelphia, 1987, pp. 305-317.

[27] Fact Sheet - Flame Resistance of Wool, Commonwealth Scientific and Industrial Research Organization, Australia, September 17, 2008. Available online at http://www.fibre2fashion.com/industry-article/8/779/flame-resistance-of-wool2.asp, accessed June 6, 2015.

[28] Lowrie, R, "Heat of Combustion and Oxygen Compatibility”, Flammability and Sensitivity of Materials in Oxygen-Enriched Atmospheres, ASTM STP 812, B. L. Werley, Ed., American Society for Testing and Materials, 1983, pp. 84-96.

[29] Totten, G. (ed.), Handbook of Hydraulic Fluid Technology, Marcel Dekker, Inc., New York, NY, 2000. ISBN: 0-8247-6022-0

[30] Werley, B L., “Oil Film Hazards in Oxygen Systems,” Flammability and Sensitivity of Materials in Oxygen-Enriched Atmospheres, ASTM STP 812, B. L. Werley, Ed., American Society for Testing and Materials, 1983, pp. 108-125.

[31] Colson, A, and Fano, E, "Filtration of Gaseous or Liquid Oxygen in Industrial Applications and Associated Fire Risks”, Flammability and Sensitivity of Materials in OxygenEnriched Atmospheres, ASTM STP 1479, D. Hirsch, R. Zawiercha, T. Steinberg, and H. Barthelemy, Eds., American Society for Testing and Materials, 2006.

[32] Fano, E., Faupin, A, and Barthelemny, H., "Selection of Metal for Oxygen Valves", Flammability and Sensitivity of Materials in Oxygen-Enriched Atmospheres, ASTM STP 1395, T. A. Steinberg, B. E. Newton, and H. D. Beeson, Eds., American Society for Testing and Materials, 2000. 